Article

\title{
Carbon Nanodots Embedded on a Polyethersulfone Membrane for Cadmium(II) Removal from Water
}

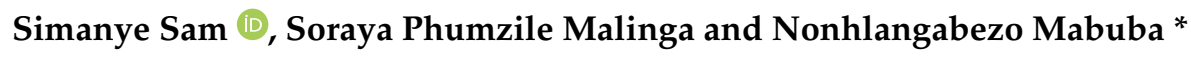

Citation: Sam, S.; Malinga, S.P.; Mabuba, N. Carbon Nanodots Embedded on a Polyethersulfone Membrane for Cadmium(II) Removal from Water. Membranes 2021, 11, 114. https://doi.org/10.3390/membranes 11020114

Academic Editor: Anja Drews

Received: 7 January 2021

Accepted: 1 February 2021

Published: 5 February 2021

Publisher's Note: MDPI stays neutral with regard to jurisdictional claims in published maps and institutional affiliations.

Copyright: (c) 2021 by the authors. Licensee MDPI, Basel, Switzerland. This article is an open access article distributed under the terms and conditions of the Creative Commons Attribution (CC BY) license (https:// creativecommons.org/licenses/by/ $4.0 /)$.
Department of Chemical Sciences (Formerly Known as Applied Chemistry), Doornfontein Campus, University of Johannesburg, P.O. Box 17011, Johannesburg 2028, South Africa; simanyesam@gmail.com (S.S.); smalinga@uj.ac.za (S.P.M.)

* Correspondence: nmabuba@uj.ac.za; Tel.: +27-11-5596158

\begin{abstract}
Cadmium(II) is a toxic heavy metal in aquatic systems. As a potential solution, green carbon nanodots (CNDs) were synthesized from oats and embedded on polyethersulfone membrane (PES) via phase inversion for the adsorption of $\mathrm{Cd}^{2+}$ from water. Characterization techniques for the CNDs and PES membranes were transmission electron microscopy (TEM), Fourier transform infrared spectroscopy (FTIR), scanning electron microscopy (SEM), Raman spectroscopy, atomic force microscopy (AFM), contact angle and a pure water flux assessment system operated at $300 \mathrm{kPa}$. TEM results showed that the CNDs were well dispersed with a uniform shape and size $(6.7 \pm 2.8 \mathrm{~nm})$. Raman spectroscopy revealed that the CNDs were embedded on the PES and the $\mathrm{I}_{\mathrm{D}} / \mathrm{I}_{\mathrm{G}}$ ratio slightly increased, showing that the membranes maintained good structural integrity.The CNDs/PES proved to be more hydrophilic than PES. The glassy carbon electrode (GCE) in anodic stripping voltammetry (ASV) technique detected $99.78 \% \mathrm{Cd}^{2+}$ removal by $0.5 \% \mathrm{CNDs} / \mathrm{PES}$ at optimum conditions: $30 \mathrm{~min}$. contact time, at $\mathrm{pH} 5$ and $0.5 \mathrm{ppm} \mathrm{Cd}^{2+}$ solution. The $0.5 \% \mathrm{CNDs} / \mathrm{PES}$ removed $\mathrm{Cd}(\mathrm{II})$ due to the hydroxyl group (-OH) and carboxyl group (-COO-) on the membrane composite. It was established that $\mathrm{Cu}^{2+}$ and $\mathrm{Pb}^{2+}$ have a significant interfering effect during the analysis of $\mathrm{Cd}^{2+}$ using GCE in ASV technique. The $0.5 \% \mathrm{CNDs} / \mathrm{PES}$ is recyclable because it removed above $95 \% \mathrm{of} \mathrm{cd}^{2+}$ in four cycles. In a spiked tap water sample, $58.38 \%$ of $\mathrm{Cd}^{2+}$ was sensed by GCE of which $95 \%$ was in agreement with the value obtained from inductively coupled plasma optical emission spectrometry (ICPOES).
\end{abstract}

Keywords: cadmium(II); polyethersulfone; membrane; carbon nanodots; electrochemical sensing

\section{Introduction}

Water contamination due to heavy metals has become a worldwide concern since the 1990s and has been a challenge for many environmental scientists [1]. The contribution of metal contamination in aquatic environments is caused by the colossal quantity of toxic heavy metals released into these environments by anthropogenic activities as well as by natural processes. These high concentrations of heavy metals are found mostly in sediments rather than in the water columns because they tend to accumulate in bottom deposits because of their higher density compared to water [2]. In portable water, wastewater and environmental water, poisonous heavy metals such as arsenic, cadmium, chromium, copper, lead and mercury are encountered [3-7]. Cadmium (II) is one of the most commonly encountered toxic heavy metals in water. It is demonstrated that +2 oxidation state is the abundant and most toxic of its compounds although it also exists in +1 state [8]. Cadmium (II) has been widely dispersed in the environment through industrial processes such as printed board manufacturing, metal finishing, plating, textile dyes, manufacturing of nickel-cadmium batteries, mining and smelting as stated by Malecki and Maron [9]. It is also distributed through human activities such as utilization of compost and discarding of $\mathrm{Ni}-\mathrm{Cd}$ batteries where the cadmium is deposited into the rivers by rain as mentioned by Fatoki and Awofolu [10]. 
Cadmium(II) can bioaccumulate in seafood and plants, which is of grave health concern as some plants and seafood are consumed by humans and animals. Human exposure to $\mathrm{Cd}^{2+}$ can lead to many types of diseases such as nephrotoxicity, kidney disease, renal function hypertension, hepatic injury, lung damage, teratogenetic effects, skeletal deformation (Itai-itai) and cardiovascular diseases [11]. $\mathrm{Cd}^{2+}$ is also a carcinogen [1,2,11,12]. South Africa has had some disputes concerning the $\mathrm{Cd}^{2+}$ levels in river water. The normal concentration of $\mathrm{Cd}^{2+}$ in freshwater should be $0.005 \mathrm{mg} / \mathrm{L}$.

In South Africa, the range guideline is 0 to $0.005 \mathrm{mg} / \mathrm{L}$ in river water for domestic use according to Department of Water Affairs and Forestry (DWAF) [13]. Water samples collected from South African water systems such as the Tyume River, Buffalo River, Keiskamma River, Umtata River and Sandile Dam, were found to have elevated concentrations of $\mathrm{Cd}^{2+}$. The concentrations ranged from 0.003 to $0.044 \mathrm{mg} / \mathrm{L}$ with the Tyume River having the highest $\mathrm{Cd}^{2+}$ concentrations of $0.030 \pm 0.002$ to $0.044 \pm 0.003 \mathrm{mg} / \mathrm{L}$. This is mainly due to the water runoffs from agricultural soils where phosphate fertilizers were used. $\mathrm{Cd}^{2+}$ is a common impurity in phosphate fertilisers $[9,11,14,15]$. Chemical precipitation, ion exchange, reverse osmosis, phytoremediation and adsorption are methods applied in heavy metal removal in water [3-7,16,17]. Adsorption is the most convenient and widely researched technique because of its ease of use and low cost [4]. Materials such as activated carbon/zicornium oxide composite activated carbon produced from rubber wood sawdust, wastewater sludge, cerium dioxide and its composites $[3,4,6,7]$. Phytoremediation is a green method that is highly promising in the alleviation of heavy metals in the environment and it is required to be more explored [5]. All the abovementioned methods are crucial for water treatment. However, their application is limited due to the a number of drawbacks: high operating costs, high costs of disposal of the precipitated sludge that is formed, performance affected by long waiting periods for plants to grow in phytoremediation, lack of control of the adsorbent in water and generally high maintenance costs due to fouling which necessitates cleaning [17]. The innovative membrane technology offers an avenue for exploration in the removal of cadmium in water and has successfully been applied in water treatment $[18,19]$. The polyethersulfone (PES) membrane possesses good chemical resistance, has an outstanding oxidative stability, has wide $\mathrm{pH}$ and temperature tolerance and mechanical strength [20]. However, membrane application in water treatment is limited due to its low hydrophilic nature and fouling [21]. Therefore, the novel aspect of our work is to improve the characteristics of PES by coating it with carbon nanodots (CNDs) which seeks to monitor and adsorb cadmium(II) from water and industrial effluents. The composite (CNDs and PES) will be reusable. A green method of synthesizing the CNDs from oats (organic cereal) was applied to produce carbon nanodots containing hydroxyl (OH-) and carboxylate (COO-) functional groups, which assisted in increasing the hydrophilicity of PES [13]. The carbon nanoparticles also have fluorescence properties, good biocompatibility and low toxicity for water treatment [13,22]. Therefore, CNDs will be embedded on a microporous membrane made of polyethersulfone (PES) to increase the membrane hydrophilicity and the removal of $\mathrm{Cd}^{2+}$ via adsorption, since they are good natural adsorbents.

\section{Materials and Methods}

\subsection{Synthesis of Carbon Nanodots and Membrane}

Commonly consumed whole grain oats (Jungle Oats) produced in South Africa was purchased from the local supermarket. Polyethesulfone (PES), polyvinylpyrrollidine (PVP) and 1-methyl-2-pyrolidinone (NMP) were purchased from Sigma Aldrich (St. Louis, MO, USA). The glassy carbon electrode (GCE), reference electrode and platinum auxiliary electrode were purchased from BASi (Newport Beach, CA, USA).

Carbon nanodots (CNDs) were synthesized according to a method reported by Shi et al. with modification. Oats $(20 \mathrm{~g})$ were placed in a crucible, transferred into a muffle furnace and pyrolyzed at $400{ }^{\circ} \mathrm{C}$ for $2 \mathrm{~h}$ instead of being microwaved [13]. The black product was cooled to room temperature and then mechanically crushed to a fine powder. The powder 
was then dispersed in ultrapure water and centrifuged several times to remove larger particles. The carbon nanodots aqueous suspension was filtered and the CND powder was obtained after drying in an oven at $80^{\circ} \mathrm{C}$ for $24 \mathrm{~h}$.

Phase inversion via immersion precipitation was used to synthesize the membranes. This method allowed for the change in phase of materials from the liquid to solid phase. Different amounts of CNDs were mixed with 1-methyl-2-pyrrolidone (NMP) and sonicated for $15 \mathrm{~min}$ to encourage dispersion (Table 1$)$. PES (16 g) and polyvinylpyrrolidine (2 g) were added to the CNDs mixture and stirred for $24 \mathrm{~h}$ to prepare the casting solution. A casting knife (Elcometer 3545 Adjustable BirdFilm Applicator, Claremont, South Africa) was used to cast $150 \mu \mathrm{m}$ membranes on a glass plate. After casting, the solutions were immediately submerged in a coagulation bath containing water (non-solvent). The membranes were further submerged into another water bath for $24 \mathrm{~h}$ to ensure that it was free from NMP. The membranes were then air dried for $24 \mathrm{~h}$ and sandwiched between plain sheets of paper for storage. The membrane composition was varied according to the percentage of CNDs added, as displayed in Table 1.

Table 1. Material amounts for composite membrane synthesis.

\begin{tabular}{ccccc}
\hline Membranes & CNDs (g) & NMP (mL) & PES (g) & PVP (g) \\
\hline Pure PES & 0 & 80 & 16 & 2 \\
0.01\% CNDs / PES & 0.01 & 80 & 16 & 2 \\
0.05\% CNDs/PES & 0.05 & 80 & 16 & 2 \\
0.5\% PES/CNDs & 0.5 & 80 & 16 & 2 \\
\hline CNDs: carbon nanodots; NMP: 1-methyl-2-pyrrolidone; PES: polyethersulfone; PVP: polyvinylpyrrollidine.
\end{tabular}

\subsection{Characterisation of Membrane Embedded with Carbon Nanodots}

The morphology and size distribution of the CNDs was characterised by TEM using JEOL JEM-2100 (Pleasanton, CA, USA). Pristine CNDs, pristine PES, $0.01 \%$ CNDs/PES, $0.05 \%$ CNDs / PES and 0.5\% CNDs/PES were analysed using a Fourier Transform Infrared (FTIR) (Perkin Elmer, Spectrum 100, Shelton, CT, USA). Raman spectroscopy was used for surface characterization of the partially ordered carbon nanodots. The Raman spectrometer Perkin Elmer, Raman Micro 200, Waltham, MA, USA, was used with an output laser power of $50 \%$. The spectra were recorded over a range of $50-3270 \mathrm{~cm}^{-1}$ using a spectral resolution of $2.0 \mathrm{~cm}^{-1}$. The hydrophilicity of the membranes was analysed using a sessile drop method on a Data Physics optical contact angle instrument (SCA 20 software, Camberley, Surrey, UK).

Scanning electron microscopy (SEM) was used to study the surface morphology and cross-sectional images of the membranes. SEM images were analysed at an accelerating voltage of $2 \mathrm{kV}$ using a TESCAN Vega TC instrument (VEGA 3 TESCAN software, Brno, Czech Republic). The SEM instrument was equipped with an X-ray detector for energy dispersive X-ray analysis (EDX), which was operated at $5 \mathrm{kV}$. The membrane's topological properties and roughness $(\mathrm{Rq})$ were analysed using a Veeco Dimension 3100 atomic force microscope (AFM) equipped with V530r3sr3 software (Plainview, NY, USA) in 3D mode at $5 \mu \mathrm{m}$ scan. The tip was mounted onto a $225 \mu \mathrm{m}$ cantilever with a spring constant of $2.8 \mathrm{~N} / \mathrm{m}$.

\subsection{Evaluation of the Membrane Performance}

Sterlitech (Kent, WA, USA) dead-end filtration system was used to evaluate the pure water flux of the pristine and modified membranes. The membranes were first compacted at $300 \mathrm{kPa}$ for $15 \mathrm{~min}$ for stabilization. Six different pressures were used for flux measurements from $300 \mathrm{kPa}, 250 \mathrm{kPa}, 200 \mathrm{kPa}, 150 \mathrm{kPa}, 100 \mathrm{kPa}$ and $50 \mathrm{kPa}$ and the flux calculated using Equation (1).

$$
j=\frac{v}{A \Delta t}
$$


where $j$ is the water flux $\left(\mathrm{L} / \mathrm{m}^{2} \mathrm{~h}\right), v$ is the permeate volume $(\mathrm{L}), A$ is the membrane area $\left(0.00146 \mathrm{~m}^{2}\right)$ and $\Delta t$ is the change in filtration time $(\mathrm{h})$.

\subsection{Adsorption of Cadmium(II) from Water Using PES Membrane Coated with Carbon Nanodots}

A method adopted from a study performed by Zhu et al. with modification was used to carry out batch adsorption experiments [23]. PES membrane $\left(16 \mathrm{~cm}^{2}\right)$ was immersed in $25 \mathrm{~mL}$ of $\mathrm{Cd}^{2+}$ synthetic solutions and shaken at different time intervals $(1,5,15,30$, 60 and $120 \mathrm{~min}$ ). The supernatants were then collected and analysed using Anodic stripping voltammetry (ASV) and inductively coupled plasma optical emission spectroscopy (ICP-OES). The effect of $\mathrm{pH}$, contact time, standard concentration and carbon nanodots concentration on membranes were investigated using ASV measurements. The amount of $\mathrm{Cd}^{2+}$ adsorbed was calculated using Equation (2).

$$
R(\%)=\frac{C_{i}-C_{f}}{C_{i}} \times 100
$$

where $C_{i}(\mathrm{mg} / \mathrm{L})$ is the initial concentration of the metal ions in aqueous solution, $C_{f}(\mathrm{mg} / \mathrm{L})$ the final concentration of the metal ions in solution. The adsorption capacity of the system was also calculated using Equation (3).

$$
\text { Adsorption capacity }=\frac{C_{i}-C_{f}}{A} \times V
$$

where $C_{i}$ is the initial concentration of $\mathrm{Cd}^{2+}, C_{f}$ is the $\mathrm{Cd}^{2+}$ concentration after adsorption $(\mathrm{mg} / \mathrm{L}), A$ is the membrane area $\left(\mathrm{cm}^{2}\right)$ and $V$ is the volume of the $\mathrm{Cd}^{2+}$ solution $(\mathrm{L})$.

\subsection{Electrochemical Detection of the Cadmium(II) Removed from Water}

Square wave anodic stripping voltammetry (SWASV) was used to detect $\mathrm{Cd}^{2+}$ in $0.1 \mathrm{M} \mathrm{HCl}$ on bare glassy carbon electrode (GCE). The deposition potential and time were $-900 \mathrm{mV}$ and $200 \mathrm{~s}$ respectively. The stripping of cadmium was achieved by scanning at a potential range between $0.6 \mathrm{~V}$ and $2 \mathrm{~V}$. The calibration studies were explored by using cadmium(II) standard solutions with concentrations ranging from 0.1 to 10 ppm under optimised conditions. In each calibration point, three replicates of SWASV measurements $(n=3)$ were done in order to minimise errors. The peak current signal increased proportionally with the increase in concentration. The linear regression equation obtained for the $\mathrm{Cd}^{2+}$ detection was found to be $\mathrm{Y}=1.4275 \times 10^{-4}+4.344906 \times 10^{-5}$ with a correlation coefficient $\left(\mathrm{R}^{2}\right)$ of 0.98489 . The limit of detection (LOD) was determined by three times multiplication of the standard deviation of the blank and division by slope of the calibration curve (3rblank/slope). The limit of quantification was (LOQ) which reflected the accepted measurements at the lowest concentration was calculated as 10\%blank/slope. The calculated LOD and LOQ were as 0.0014 and $0.0046 \mathrm{ppm}$ respectively. The bare GCE electrode was applied in the detection of cadmium in real water sample and the results were validated by inductively coupled plasma optical emission spectroscopy.

\section{Results}

\subsection{Characterisation of the Membrane}

The TEM images of the carbon nanodots are shown in Figure 1a. The TEM micrograph illustrated a mean particle size of $36.9 \pm 11.0 \mathrm{~nm}$ for the carbon nanomaterials before it was mechanically ground to a fine powder. Well-dispersed and spherical carbon nanodots with uniform shape and size in the range of 2 to $10 \mathrm{~nm}$ with an average of $6.7 \pm 2.8 \mathrm{~nm}$ were attained after mechanical grinding (Figure 1b). Similar results were observed by Shi et al., who synthesised duel emission carbon nanodots from naked oats via pyrolysis and mechanical grinding. In their study the majority of the carbon nanodots were in the range of 7 to $11 \mathrm{~nm}$ with an average mean of $8.64 \pm 0.84 \mathrm{~nm}$ [13]. After the addition of CNDs, the 
surface of the membrane becomes more porous with fewer macrovoids. Consequently, the surface area was increased and more adsorption sites will be available for $\mathrm{Cd}^{2+}$ adsorption.
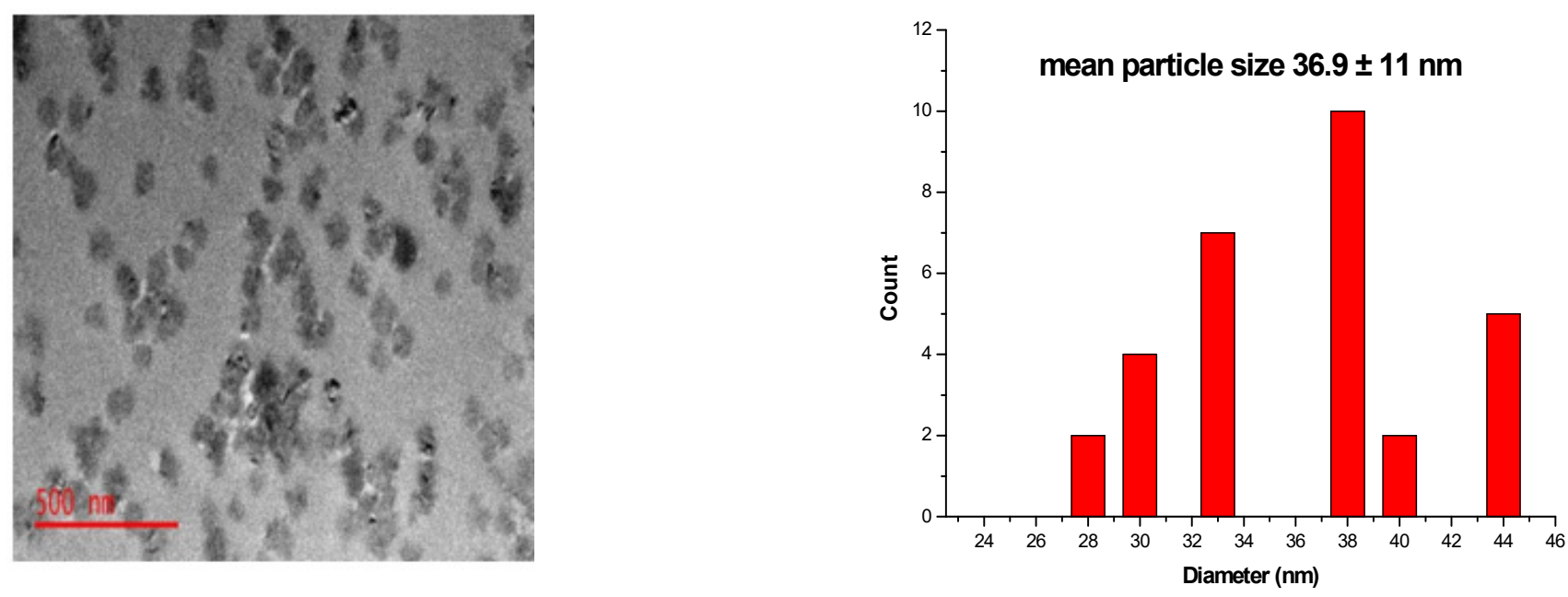

(a)
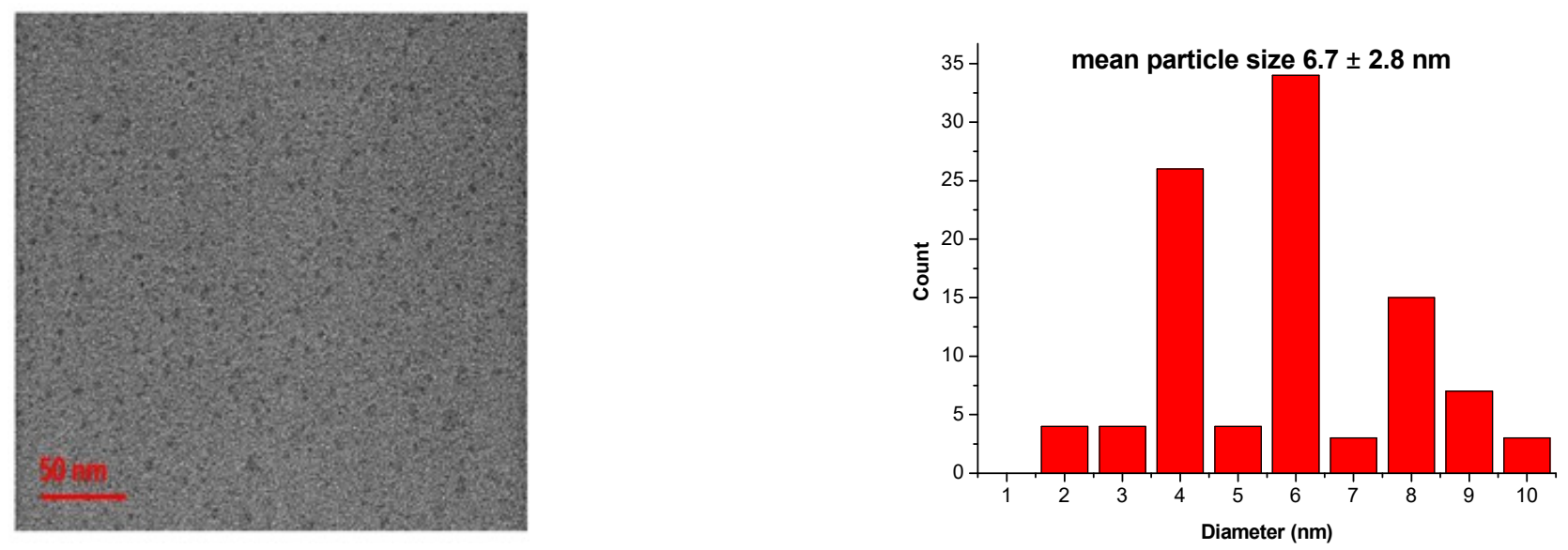

(b)

Figure 1. Characterization of the polyethersulfone (PES) and Carbon nanodots coated on polyethersulfone (CNDs/PES) using transmission electron microscopy (TEM). (a) before grinding; (b) after grinding.

Fourier transform infrared spectroscopy (FTIR) analysis of the pure oats and CNDs is displayed in Figure 2a The pure oats had characteristic peaks at $3441 \mathrm{~cm}^{-1}, 2920 \mathrm{~cm}^{-1}$, $1628 \mathrm{~cm}^{-1}, 1399 \mathrm{~cm}^{-1}$ and $1147 \mathrm{~cm}^{-1}$ ascribed to $-\mathrm{O}-\mathrm{H},-\mathrm{COO}^{-}, \mathrm{C}=\mathrm{C}$ and -C-O-stretch respectively. Similar peaks were observed for the CNDs as illustrated in Figure 2a. The CNDs characteristic peaks were detected at $3441 \mathrm{~cm}^{-1}, 2920 \mathrm{~cm}^{-1}, 1628 \mathrm{~cm}^{-1}, 1399 \mathrm{~cm}^{-1}$ and $1147 \mathrm{~cm}^{-1}$ ascribed to $-\mathrm{O}-\mathrm{H}, \mathrm{C}-\mathrm{H}, \mathrm{COO}-, \mathrm{C}=\mathrm{C}$, and $-\mathrm{C}-\mathrm{O}$ stretching vibrations respectively. This trend was also observed by Shi et al. In their study, similar observations of peaks $3426 \mathrm{~cm}^{-1}, 3151 \mathrm{~cm}^{-1}, 1634 \mathrm{~cm}^{-1}$ and $1400 \mathrm{~cm}^{-1}, 1114 \mathrm{~cm}^{-1}$ and $1165 \mathrm{~cm}^{-1}, 952 \mathrm{~cm}^{-1}$ were attributed to the $\mathrm{O}-\mathrm{H}, \mathrm{C}-\mathrm{H}$ (stretching vibrations), $\mathrm{COO}-, \mathrm{C}-\mathrm{O}$ and $\mathrm{O}-\mathrm{H}$ (bending vibrations) respectively. 


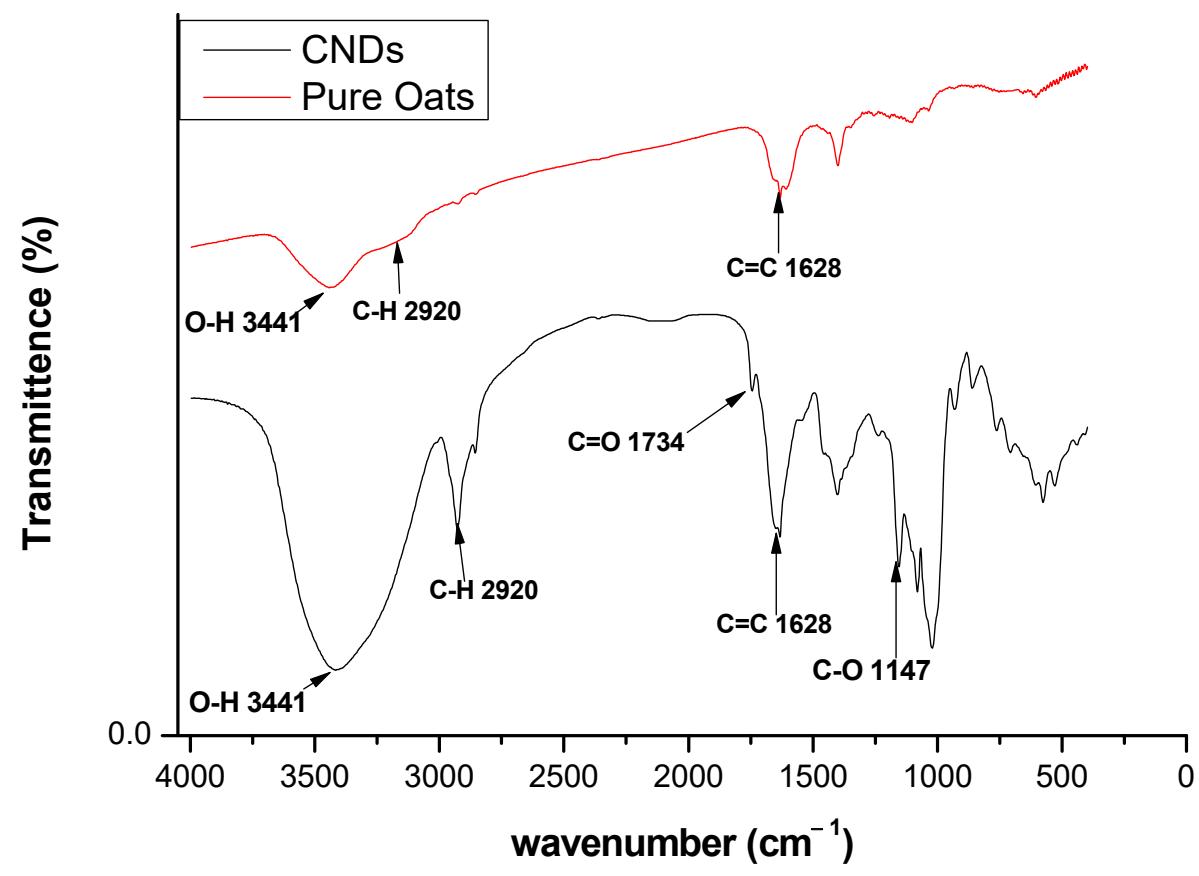

(a)

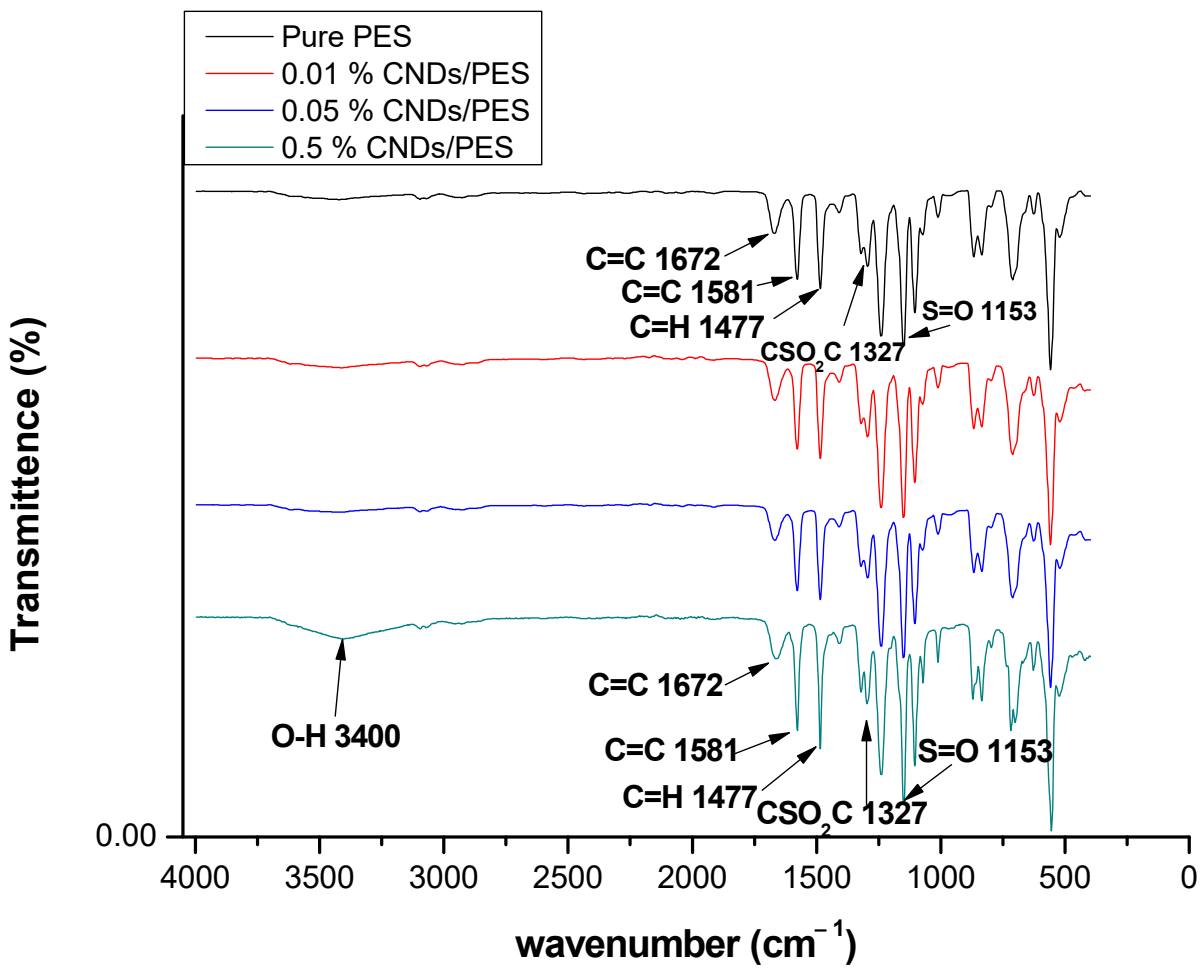

(b)

Figure 2. Characterization of the polyethersulfone (PES) and carbon nanodots coated on the polyethersulfone (CNDs/PES) using Fourier transform infrared spectroscopy (FTIR). (a) pure oats and CNDs; (b) PES and (CNDs/PES).

Structural modification of PES using CNDs was also determined using FTIR in Figure $2 b$. The characteristic FTIR analysis and the respective peaks for pristine PES were observed at $1600 \mathrm{~cm}^{-1}$ and $1400 \mathrm{~cm}^{-1}$ for aromatic skeletal vibrations, $1324 \mathrm{~cm}^{-1}$ and $1239 \mathrm{~cm}^{-1}$ for C-O-C stretching and $1151 \mathrm{~cm}^{-1}$ and $1105 \mathrm{~cm}^{-1}$ for pristine PES membranes. 
The results are in agreement with other reports [24]. Blending the PES with CNDs introduced a new functionality at $3400 \mathrm{~cm}^{-1}$ which was attributed to -OH due to the presence of CNDs. The PES peaks observed between $1672 \mathrm{~cm}^{-1}$ to $500 \mathrm{~cm}^{-1}$ could mask the absent peaks from CNDs. Further analysis in the following sections, however, clarify the presence of CNDs within the membranes.

Figure 3 displays the Raman spectra for pure CNDs, $0.01 \%$ CNDs/PES, $0.05 \%$ CNDs/PES and $0.5 \% \mathrm{CNDs} / \mathrm{PES}$ membranes. The pure CNDs spectra showed two peaks which are generally attributed to the D-band at approximately $1339.02 \mathrm{~cm}^{-1}$ and G-band at $1567.64 \mathrm{~cm}^{-1}$ [25] For the modified membranes, these analyses generally showed the $\mathrm{G}$ and $\mathrm{D}$ band at $\sim 1337.58 \mathrm{~cm}^{-1}$ and $\sim 1592.69 \mathrm{~cm}^{-1}$ respectively. The $\mathrm{G}$ band is attributed to intrinsic vibrations of $\mathrm{sp}^{2}$ bonded graphitic carbon, whilst the $\mathrm{D}$ band corresponds to defects induced in the CNDs due to the disruption of $-\mathrm{C}=\mathrm{C}$ bonds [26]. The $\mathrm{G}$ band was higher than the $\mathrm{D}$ band, showing good structural integrity of the CNDs. After blending the PES with CNDs, the $\mathrm{I}_{\mathrm{D}} / \mathrm{I}_{\mathrm{G}}$ ratio slightly increased to $0.74,0.79,0.83$ and 0.82 for Pure CNDs, $0.01 \%$ CNDs/PES, $0.05 \%$ CNDs/PES and $0.5 \%$ CNDs/PES respectively as demonstrated in Table 2 , the addition of the CNDs to the pure PES increased the $\mathrm{I}_{\mathrm{D}} / \mathrm{I}_{\mathrm{G}}$ ratio, which means that the membrane maintained good structural integrity as it was increasing to closer to one [27].

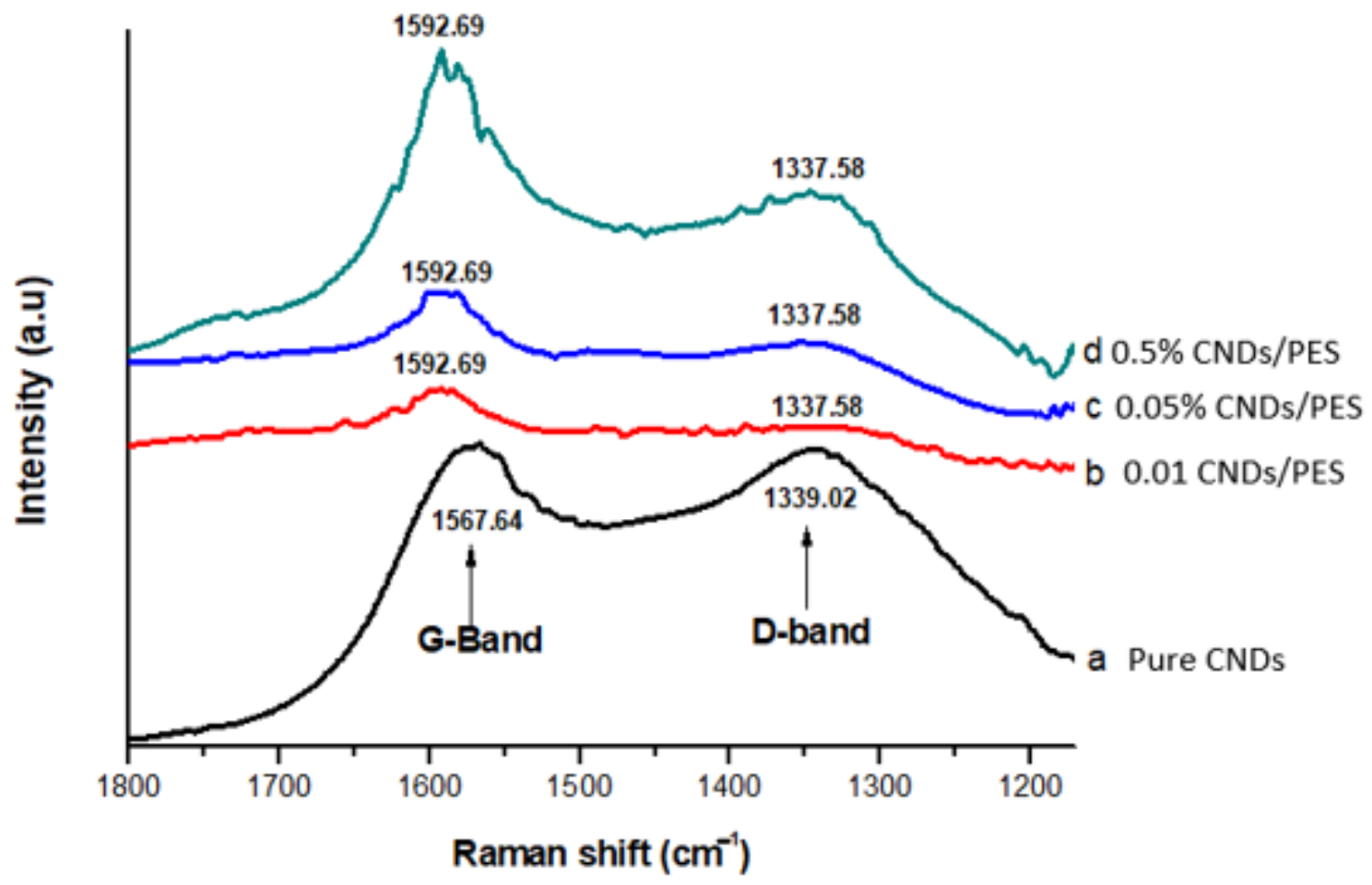

Figure 3. Characterizfation of the polyethersulfone (PES) and carbon nanodots embedded on polyethersulfone (CNDs/PES) using Raman spectra.

Table 2. $\mathrm{I}_{\mathrm{D}} / \mathrm{I}_{\mathrm{G}}$ ratio and carbon nanodots embedded membrane composites.

\begin{tabular}{cccc}
\hline \multirow{2}{*}{ Sample } & \multicolumn{2}{c}{ Peak Position/cm } & \\
\cline { 2 - 3 } & D-Band & G-Band & $\mathbf{I}_{\mathbf{D}} / \mathbf{I}_{\mathbf{G}}$ \\
\hline Pure CNDs & 1339.02 & 1567.64 & 0.74 \\
$0.01 \%$ CNDs /PES & 1337.58 & 1567.64 & 0.79 \\
$0.05 \%$ CNDs/PES & 1337.58 & 1567.64 & 0.83 \\
$0.5 \%$ CNDs/PES & 1337.58 & 1567.64 & 0.82 \\
\hline
\end{tabular}

Figure 4a-d illustrates scanning electron microscopy (SEM) images of the surface and cross-section of PES and CNDs/PES membranes. The surface of PES is homogeneous and 
smooth without obvious voids or defects (Figure 4a) in comparison to the CNDs/PES membranes (Figure $4 \mathrm{~b}-\mathrm{d}$ ). The CNDs/PES membranes presented a relatively spongy and porous surface as the amount of the CNDs was increased. The pure PES membrane showed a uniform thin finger-like structure. The tear-shaped elongated micro voids were observed extending towards the permeate side of the membrane (Figure $4 \mathrm{a}$ ). As the CNDs concentration was increased, the macro voids within the membranes became more pronounced. In 0.01\% CNDs/PES (Figure 4b), 0.05\% CNDs/PES (Figure 4c) and 0.5\% CNDs/PES (Figure 4d) membranes, a more pronounced cross-sectional asymmetry was observed. The elongated narrower macro voids of pure PES transitioned into wider macro voids that spanned the entire cross-section of the membrane. Orooji et al. observed a similar trend in their study of nano-structured carbon polyethersulfone composite ultrafiltration membrane with significantly low protein adsorption and bacterial adsorption adhesion [28]. In this study it was observed that the increase in viscosity due to addition of the mesoporous carbon leads to a slower solvent exchange process and eventually formed larger finger-like pores [28].
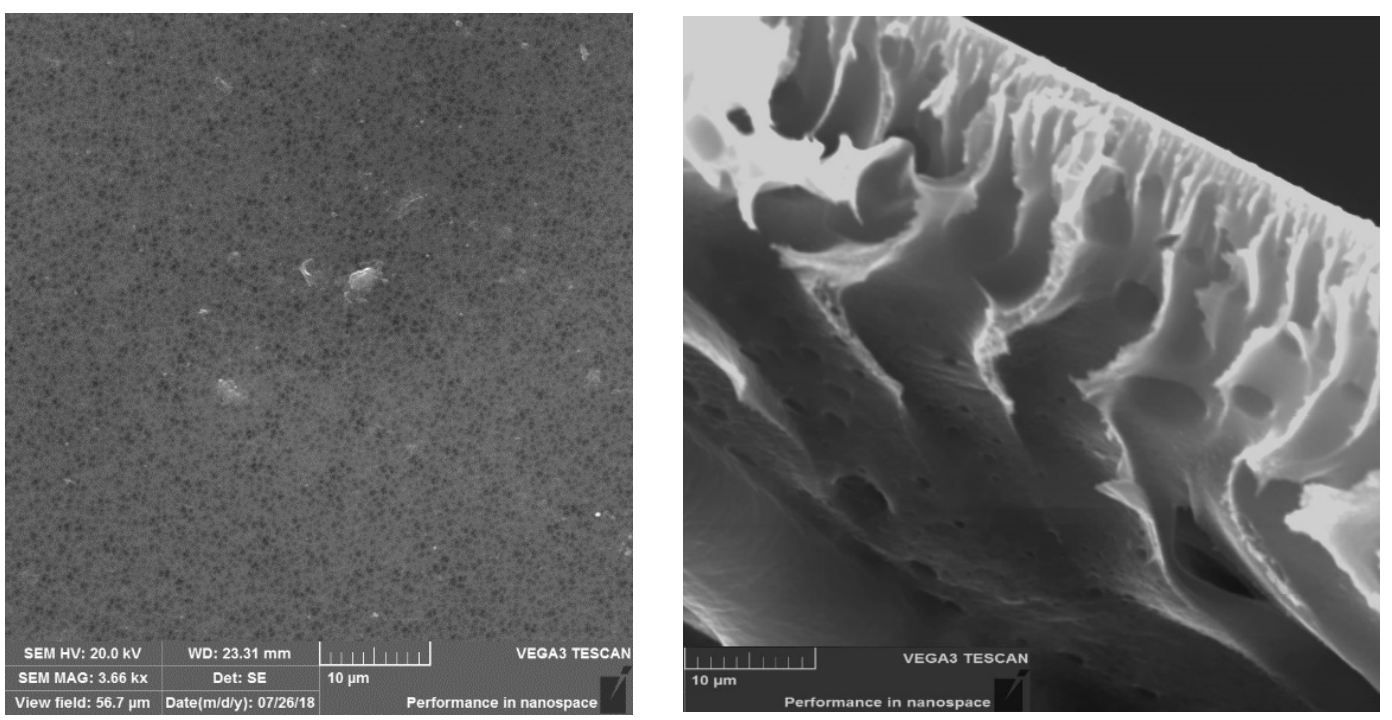

(a)
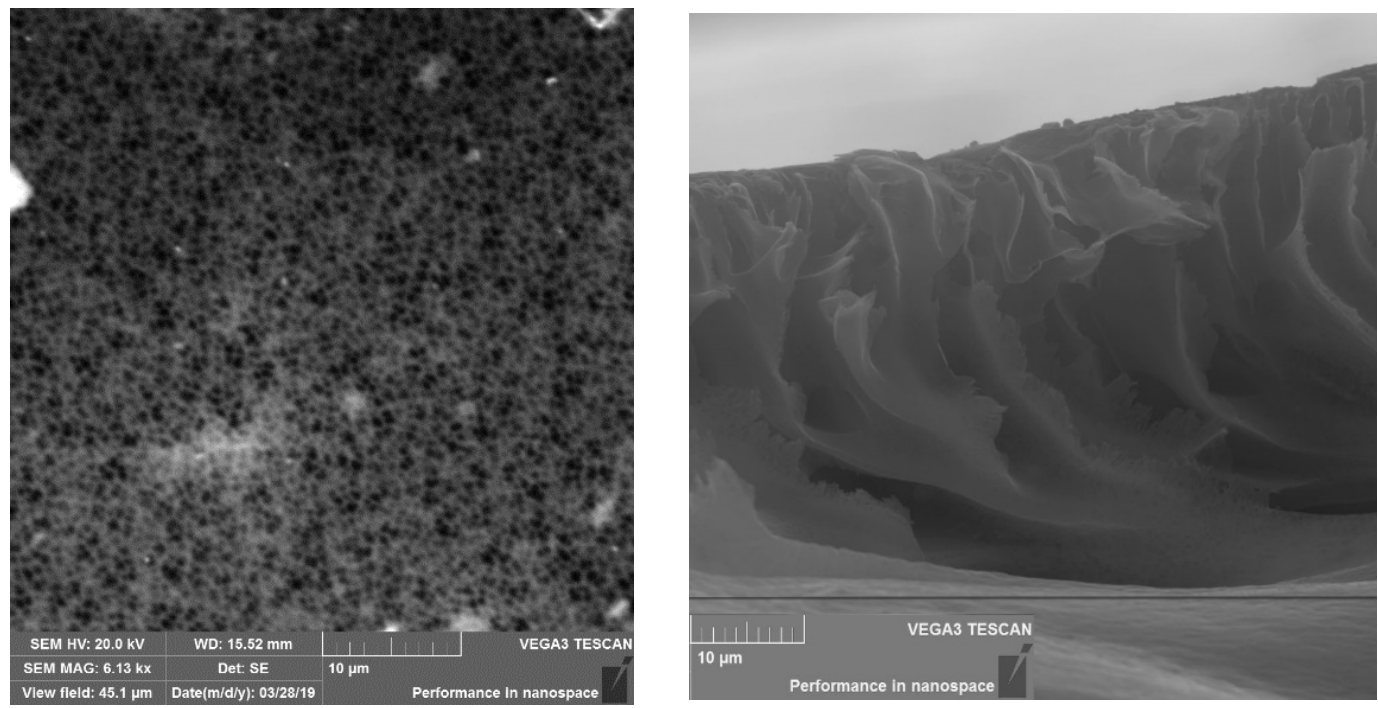

(b)

Figure 4. Cont. 

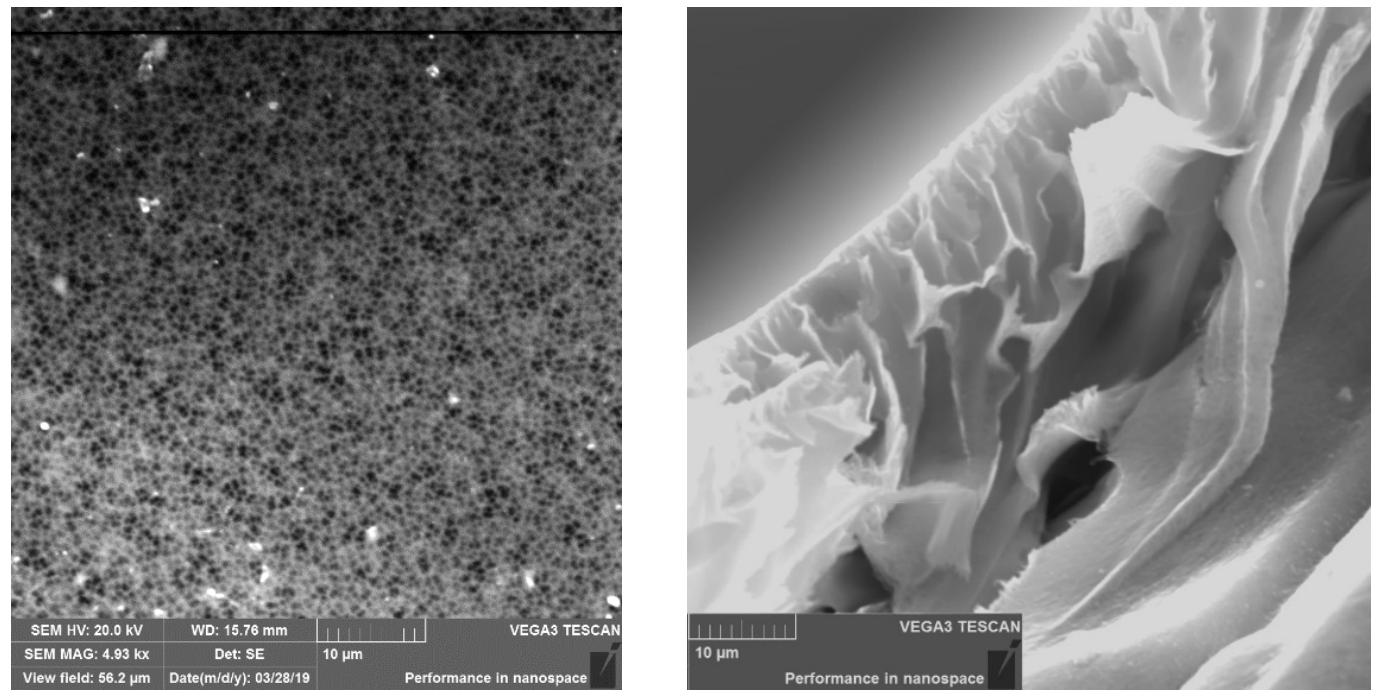

(c)
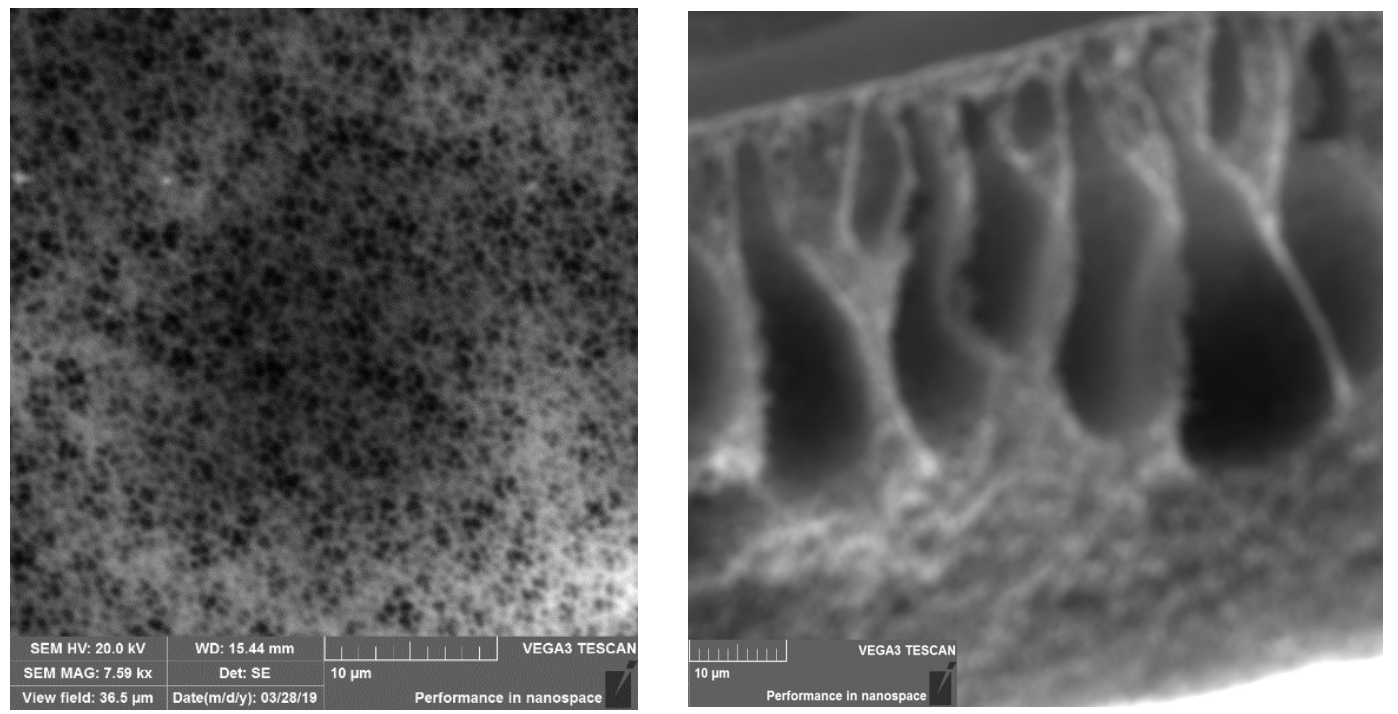

(d)

Figure 4. Characterization of the PES and CNDs/PES using scanning electron microscopy (SEM). (a) pure PES; (b) 0.01\% CNDs/PES; (c) $0.05 \%$ CNDs/PES (d) $0.5 \%$ CNDs/PES.

Atomic force microscopy (AFM) analysis was investigated out in $3 \mathrm{D}$ mode at $5 \mu \mathrm{m}$ to observe the changes in surface topography as displayed in Figure 5. In Figure 5a, it was observed that the surface of the pristine PES was smooth compared to the CND embedded membranes. The rougher surface of the embedded membranes was created by the addition of the CNDs to the pure PES (Figure $1 b-d$ ). The CND embedded membranes also showed a varied ridge-and-valley structure as compared to the more uniform ridge-and-valley structure of the pristine PES. The roughness measurements $\left(R_{q}\right)$ in Table 3 were found to confirm the aforementioned results. The roughness measurements were 16.4, 21.9, 23.7 and $35.9 \mathrm{~nm}$ for pristine PES, 0.01\% CNDs/PES (Figure 5b), 0.05\% CNDs/PES (Figure 5c) and $0.5 \%$ CNDs /PES (Figure 5d), respectively. Therefore, the surface roughness increased with the increased amount of CNDs embedded to the membranes. Yuan et al. also reported that the incorporation of CNDs into their polyethyleneimine (PEI) matrix, dip-coated on polyacrylonitrile support, led to an increase in surface roughness [29]. 


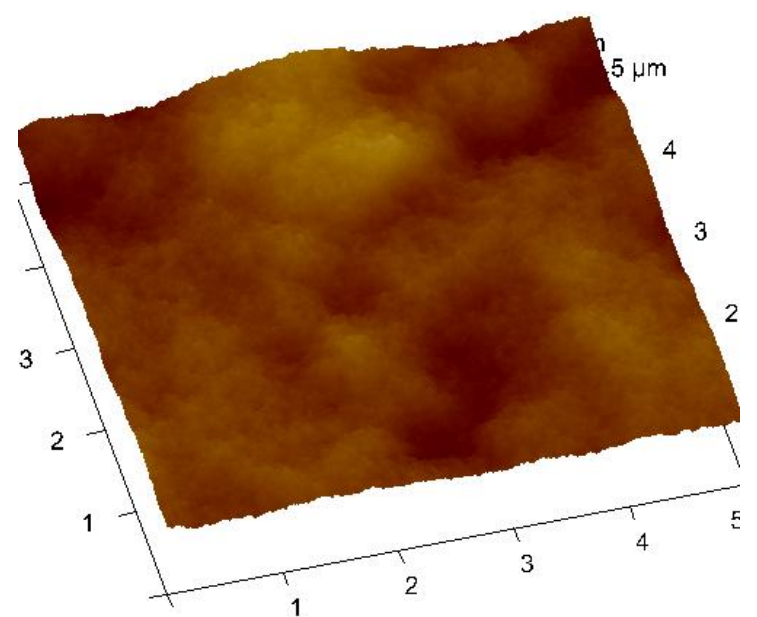

(a)

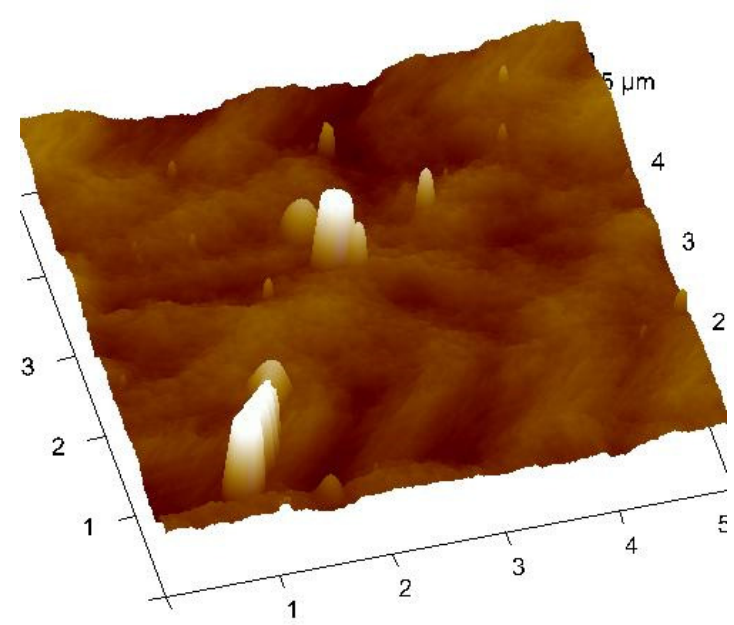

(c)

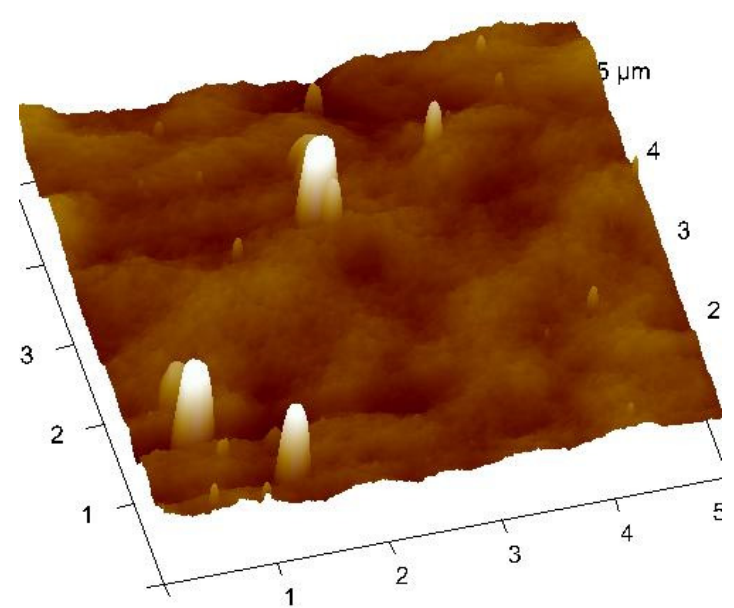

(b)

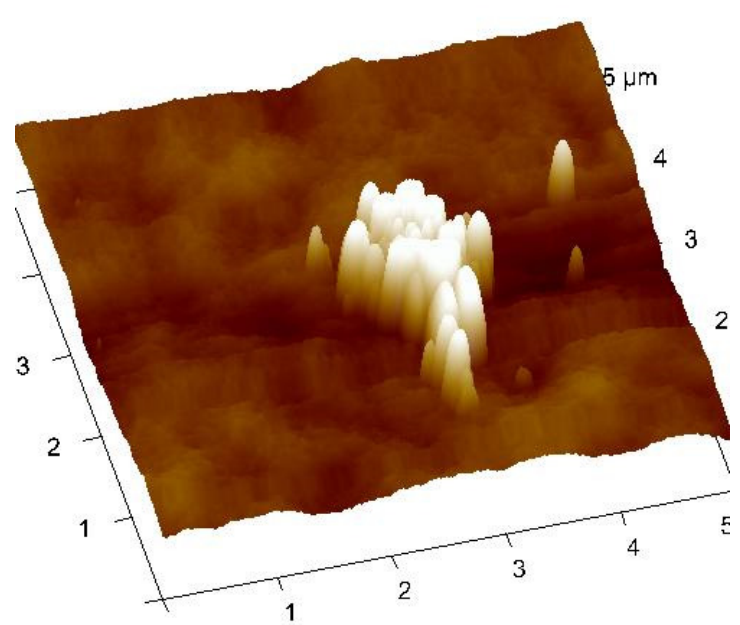

(d)

Figure 5. Characterization of the PES and CNDs/PES using atomic force microscopy (AFM). (a) pure PES; (b) $0.01 \%$ CNDs/PES; (c) $0.05 \%$ CNDs / PES (d) $0.5 \%$ CNDs/PES.

Table 3. AFM statistical data.

\begin{tabular}{cc}
\hline Membrane & $\begin{array}{c}\text { Surface Roughness (Rq) } \\
\text { (nm) }\end{array}$ \\
\hline Pristine PES & 16.4 \\
$0.01 \%$ CNDs/PES & 21.9 \\
$0.05 \%$ CNDs /PES & 23.7 \\
$0.5 \%$ CNDs/PES & 35.9 \\
\hline
\end{tabular}

The water contact angle analysis in this study was performed using the sessile drop method. This was done to investigate the hydrophilic nature of the membranes. Figure 6 shows the contact angle analysis of the pristine PES, $0.01 \%$ CNDs/PES, $0.05 \%$ CNDs / PES and $0.5 \%$ CNDs/PES modified membranes. The contact angle of pristine PES, $0.01 \%$ CNDs/PES, $0.05 \%$ CNDs/PES and $0.5 \%$ CNDs/PES were $73.4^{\circ} \pm 2.5^{\circ}, 68.2^{\circ} \pm 7.8^{\circ}$, $64.8^{\circ} \pm 3.1^{\circ}$ and $60.5^{\circ} \pm 3.7^{\circ}$ respectively. The increased amount of CNDs reduced the contact angle, i.e., it improved the hydrophilicity of the membranes. This enhancement 
in hydrophilicity was attributed to the presence of hydrophilic functional groups such as $-\mathrm{OH}$ and $\mathrm{COO}^{-}$found in the CNDs as reported in the FTIR analysis. A similar trend was observed by Orooji et al. [29] in whose study it was witnessed that, due to the added carbonyl functional groups of the mesoporous carbon, the contact angle of the control PES decreased, which meant that the membrane became more hydrophilic.

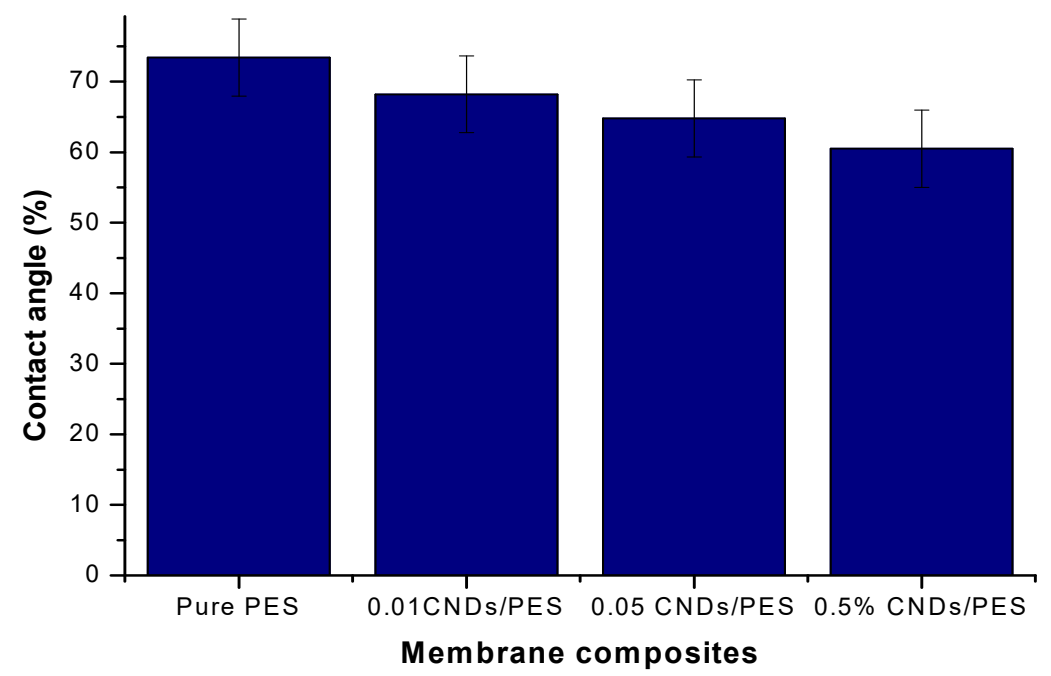

Figure 6. Characterization of the PES and CNDs/PES using Contact angle.

\subsection{Membrane Performance}

Pure water flux of pristine PES, 0.01\% CNDs/PES, 0.05\% CNDs/PES and 0.5\% CNDs/PES composite membranes are demonstrated in Figure 7. At a constant pressure of $300 \mathrm{kPa}$, the flux of pristine PES, 0.01\% CNDs/PES, 0.05\% CNDs/PES and 0.5\% CNDs/PES was $60.00,96.93,142.16$ and $196.62 \mathrm{~L} \mathrm{~m}^{-2} \mathrm{~h}^{-1}$, respectively. The pure water flux increased with increase in CND concentration in the membranes as compared to the pristine PES. This was due to the hydrophilic nature of the CNDs, which is known to increase water flux [30]. Zinadini and Ghalami had similar findings in a study investigating the preparation and characterization of high flux PES nanofiltration membrane using hydrophilic nanoparticles by phase inversion method for application in advanced wastewater treatment [20].

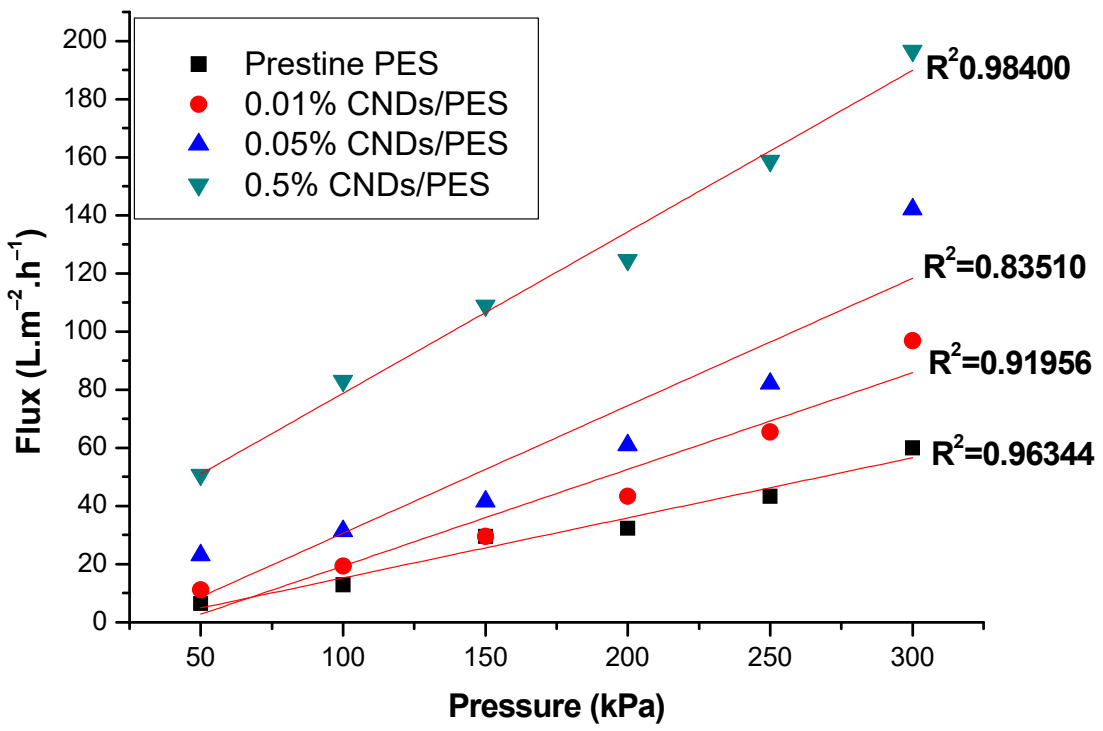

Figure 7. The relationship between pure water flux and pressure in PES and CNDs/PES membranes. 


\subsection{Characterization of Glassy Carbon Electrode (GCE) for Cadmium(II) Determination}

The bare GCE was electrochemically characterised using cyclic voltammetry (CV) at a potential range of -0.200 to $0.600 \mathrm{~V}$ at a scan rate of $50 \mathrm{mV} \mathrm{s}^{-1}$ in in $\left[\mathrm{Fe}(\mathrm{CN})_{6}\right]^{-3 /-4}$ redox probe as depicted in Figure 8a. The cadmium(II) peak was observed at $0.200 \mathrm{~V}$. It was observed that for the reversible redox couple, peak current increased with the scan rate at the same potential window. The current signal from the bare GCE is an analytical indicator that the electrode can be used as a suitable platform for electro analysis of cadmium(II) in water.

In this study, the highest stripping current for $\mathrm{Cd}^{+2}$ in different electrolytes was obtained by using $0.1 \mathrm{M} \mathrm{HCl}$ as an electrolyte (Figure $8 \mathrm{~b}$ ). The supporting electrolyte plays a major role in reducing the internal resistance and electron migration. Since the $\mathrm{pH}$ affects the availability of cadmium during stripping, it was varied $(1,2,4,5,6,8,10)$ and $\mathrm{pH}=5$ was the optimum acidity as displayed in Figure 8c.

The optimisation of the deposition time and potential of $\mathrm{Cd}^{2+}$ for stripping on the electrode surface is crucial because it facilitates control of cadmium concentration on the electrode surface to enhance the sensor sensitivity. An electrodeposition potential of $-900 \mathrm{mV}$ (Figure 8d) and electrodeposition time of $200 \mathrm{~s}$ were chosen as optimized parameters for the pre-concentration step (Figure 8e).

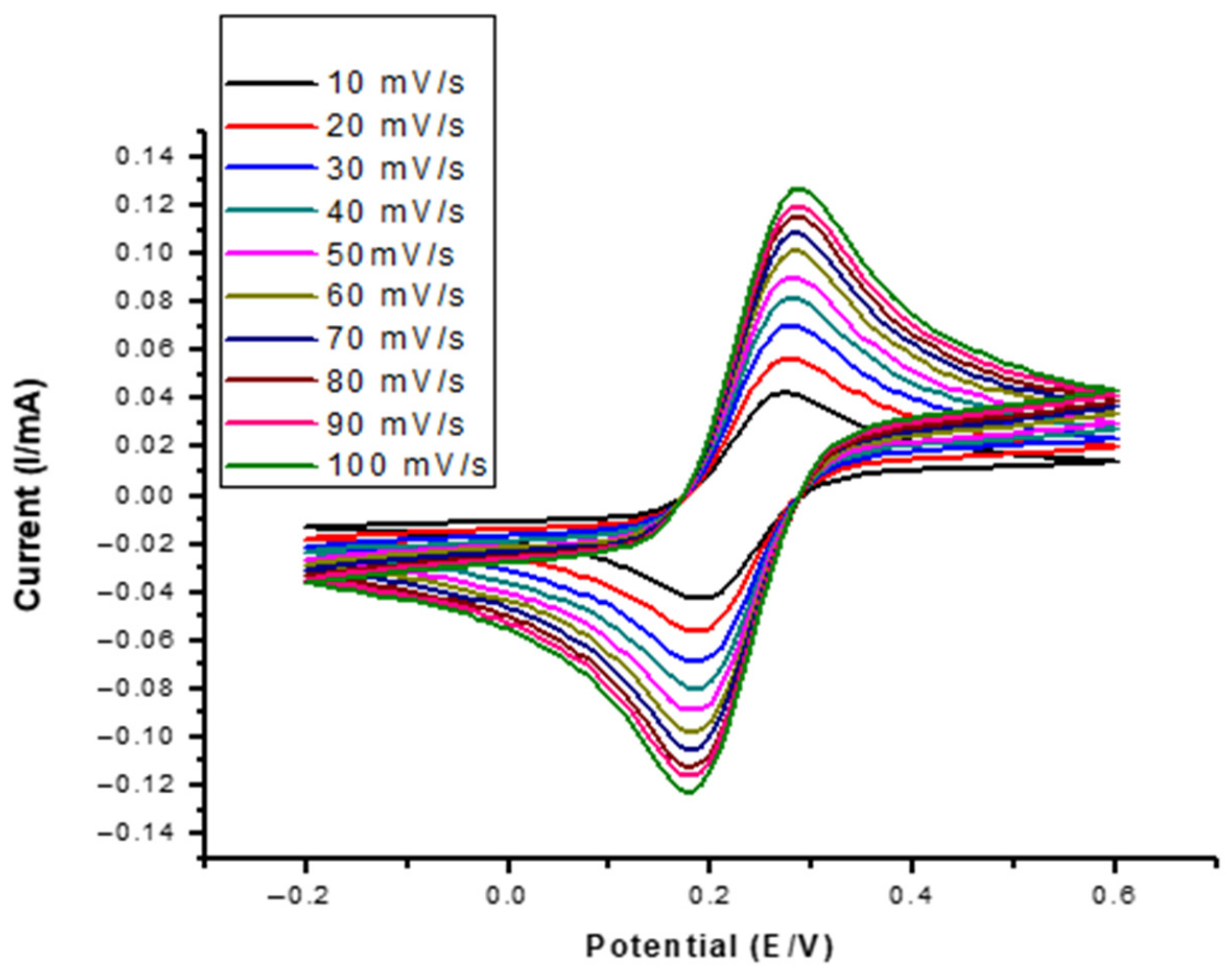

(a)

Figure 8. Cont. 


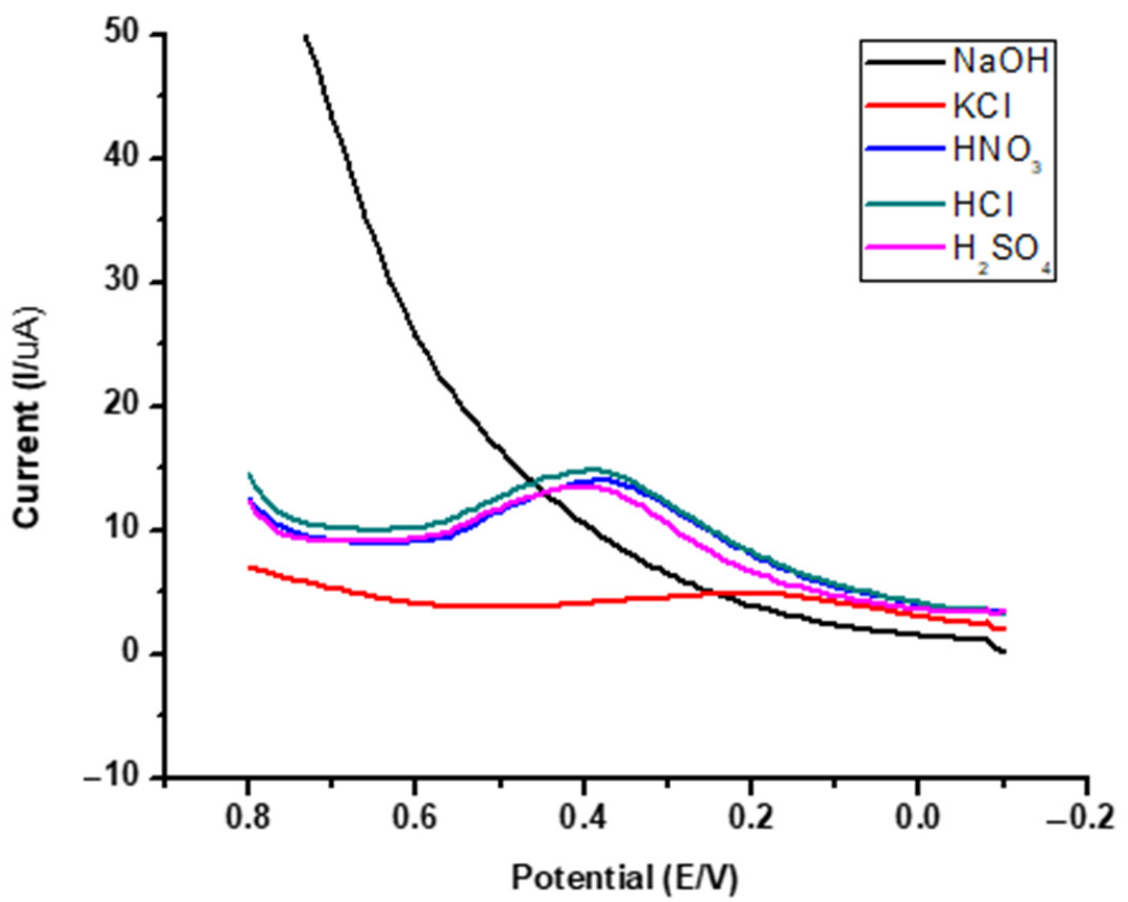

(b)

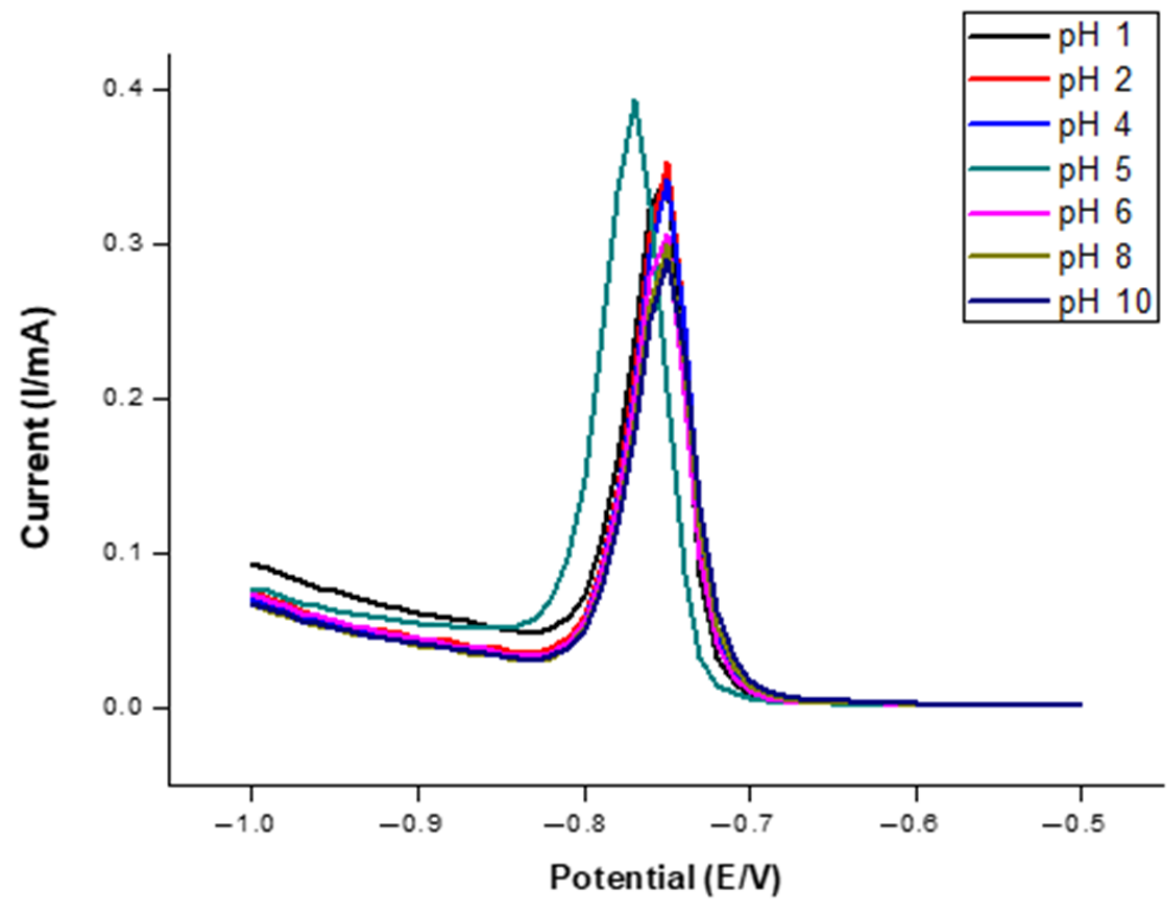

(c)

Figure 8. Cont. 


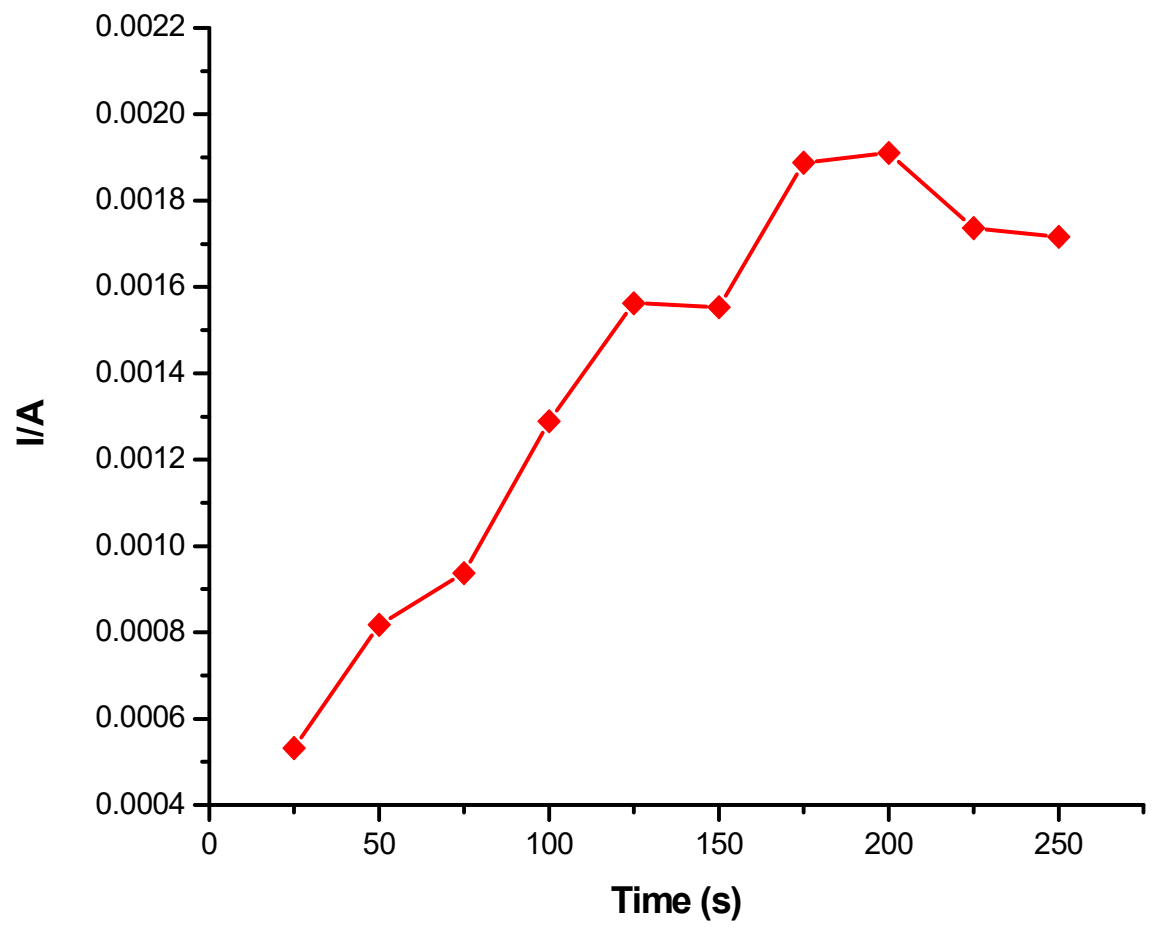

(d)

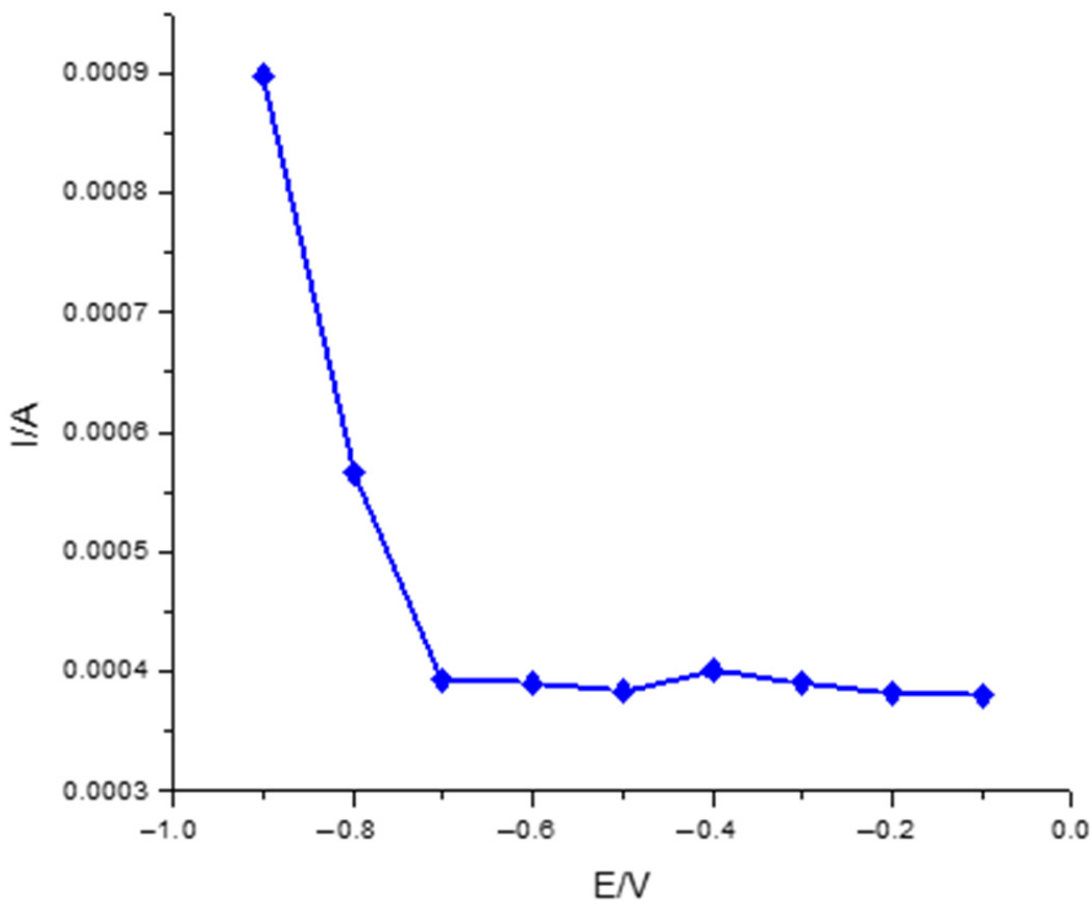

(e)

Figure 8. (a) Cyclic Voltammetry multi-scan of bare GCE in $10 \mathrm{mM}\left[\mathrm{Fe}(\mathrm{CN})_{6}\right]^{3-/ 4-}$ redox probe and optimization of: (b) electrolytes, (c) pH (d) deposition time, and (e) deposition potential. 


\subsection{Electrochemical Detection of Cd(II) Using GCE}

At optimized conditions $(0.1 \mathrm{M} \mathrm{HCl}, 200 \mathrm{~s}$ deposition time and $-900 \mathrm{mV}$ deposition potential), GCE electrodes gave an increased current response during the stripping of $10 \mathrm{ppm}$ cadmium at a potential of $0.200 \mathrm{~V}$.

The adsorption of $\mathrm{Cd}^{2+}$ from $10 \mathrm{ppm}$ standard solution was done by using five membranes, which were: pure PES membrane, $0.01 \%$ CNDs/PES, $0.05 \%$ CNDs/PES and $0.5 \%$ CNDs/PES. Figure 9 shows that $0.5 \%$ CNDs/PES composite was the most efficient membrane composite during $\mathrm{Cd}^{2+}$ adsorption because a higher percentage removal of $46.81 \%$ was achieved. This proved that $0.5 \%$ CNDs embedded on the membrane created more sites for the adsorbate $\left(\mathrm{Cd}^{2+}\right)$ to bind onto the composite membranes. In most studies, where carbon-based nanomaterials are used, higher loadings (above $0.4 \%$ or above $0.5 \%$ ) affected properties such pore size, hydrophilicity, antifouling properties and roughness of the membrane. This is due to the fact that high loadings cause agglomeration of the nanomaterial $[31,32]$.

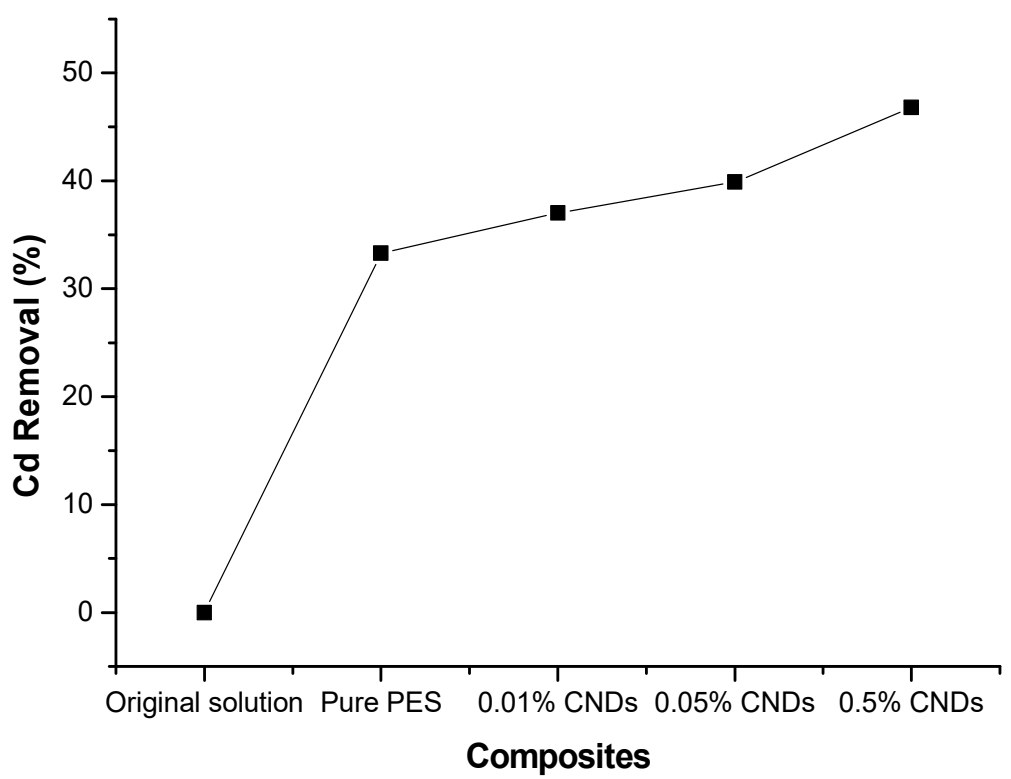

Figure 9. Effect of different membrane composition for the removal of cadmium(II) from standard solutions.

The electrochemical response during cadmium(II) sensing at different $\mathrm{pH}$ values before and after adsorption of $\mathrm{Cd}^{2+}$ from $10 \mathrm{ppm}$ standard solution by $0.5 \% \mathrm{CNDs}$ on PES membrane was investigated. The adsorption of Cd(II) ions by the $0.5 \%$ CNDs/PES membrane was the highest at $\mathrm{pH} 5$ and $\mathrm{pH} 6$, which was 76.08 and $53.62 \%$, respectively as shown in Figure 10. pH studies are mandatory because the ionic states of the analytes depend on the acidity of the surrounding medium [33].

At $\mathrm{pH} 1, \mathrm{pH} 2, \mathrm{pH} 4$ and $\mathrm{pH} 8$, the \% removal of cadmium(II) was 9.67, 6.89, 13.7 and $23.49 \%$, respectively (Figure 10 ). This was due to the fact that at a strong acidic medium (below $\mathrm{pH} 3$ ) the concentration of the $\mathrm{H}^{+}$ions on the surface of the membrane is high and there is a competition between these ions and Cd(II), for active sites on the membrane [24]. At this $\mathrm{pH}$ the ionic interactions between the carbon nanodots and the cadmium ion is increased. This is because of the dissociation degree of the functional groups $(-\mathrm{O}-\mathrm{H},-\mathrm{COO}-$ and -C-O-) to form negatively charged species on the membrane surface. This, therefore facilitates electrostatic interaction between the positively charged cadmium ions and the negatively charged oxygen molecules on the membrane surface. Therefore $\mathrm{pH} 5$ was used as the optimum working $\mathrm{pH}$ to avoid the precipitation of cadmium as hydroxides at a $\mathrm{pH}$ above 6. A similar trend was reported by Tshwenya and Arotiba [34]. 


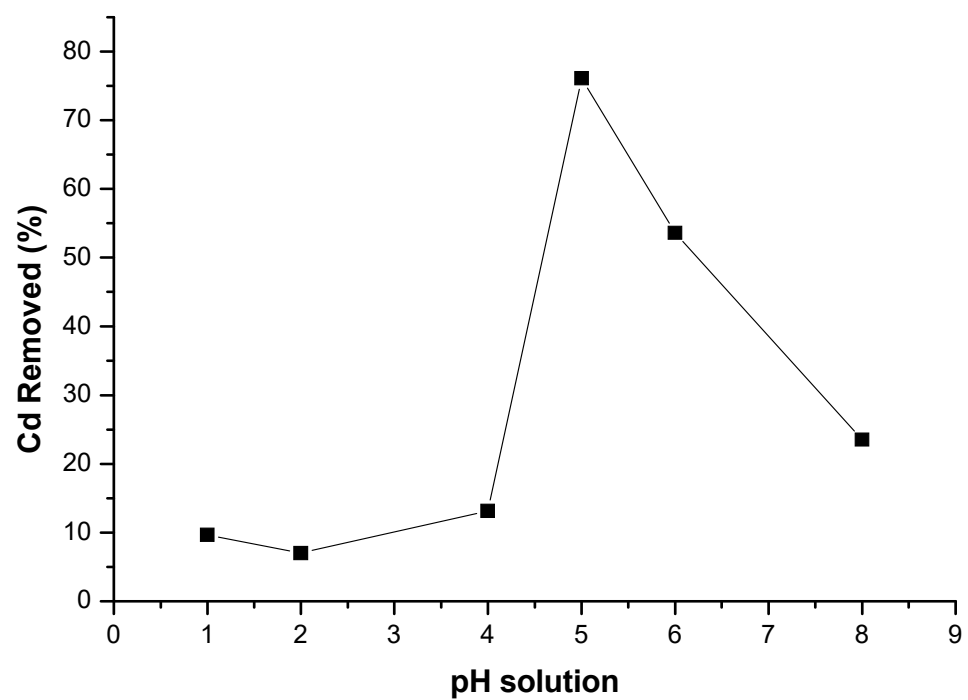

Figure 10. Effect of $\mathrm{pH}$ for the removal of cadmium(II) from standard solutions.

The effect of the contact time in removing $\mathrm{Cd}^{2+}$ from $10 \mathrm{ppm}$ standard solution was optimised by applying Pure PES, 0.01\% CNDs/PES, 0.05\% CNDs/PES and $0.5 \%$ CNDs/PES membranes for $60 \mathrm{~min}$. The current signals for all membranes decreased for the first $30 \mathrm{~min}$, which meant that adsorption of $\mathrm{Cd}^{2+}$ took place within that period (Figure 11). Thereafter, there was a sharp increase from $30 \mathrm{~min}$ to $60 \mathrm{~min}$. This trend was as a result of the CND concentration gradient: as the contact time between the composite membrane and $\mathrm{Cd}(\mathrm{II})$ solution increased, more $\mathrm{Cd}(\mathrm{II})$ ions were able to reach additional adsorption active sites until equilibrium was reached. The $0.5 \%$ CNDs/PES membrane composite demonstrated the highest adsorption efficiency compared to pure PES, $0.01 \%$ CNDs/PES and $0.05 \%$ CNDs/PES composite membranes. This was due to the increase of the CNDs embedded to the PES membrane, which increased the active sites of the composite membrane; $0.5 \%$ CNDs/PES membrane removed most Cd(II) $(46.81 \%)$ at $\mathrm{pH} 5$ within $30 \mathrm{~min}$ of treatment. There was no further increment in percentage removal with the increasing time and this could be due to the saturation of the $\mathrm{Cd}(\mathrm{II})$ ions in the membrane. The optimum time was therefore $30 \mathrm{~min}$ for this study.

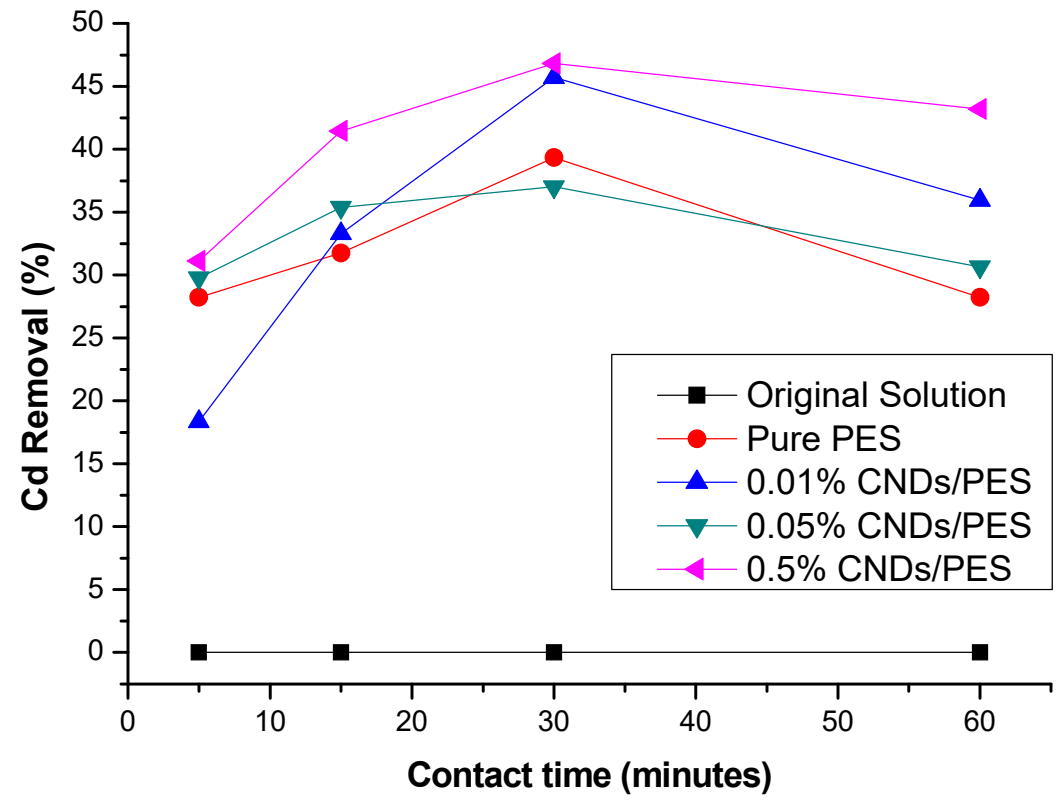

Figure 11. Effect of contact time for the removal of cadmium(II) from standard solutions. 
Different standard concentrations of $\mathrm{Cd}^{2+}(0.5 \mathrm{ppm}, 1 \mathrm{ppm}, 1.5 \mathrm{ppm}, 5 \mathrm{ppm}$ and $10 \mathrm{ppm}$ ) were used in determining the percentage adsorbed for $\mathrm{Cd}(\mathrm{II})$ ions for $30 \mathrm{~min}$ at pH 5 using the different membrane composites. As observed in Figure 12, the percentage Cd(II) adsorbed by pure PES, 0.01 CNDs/PES, 0.05 CNDs/PES and 0.5 CNDs/PES was $95.71,96.32,97.69$ and $99.78 \%$, respectively.

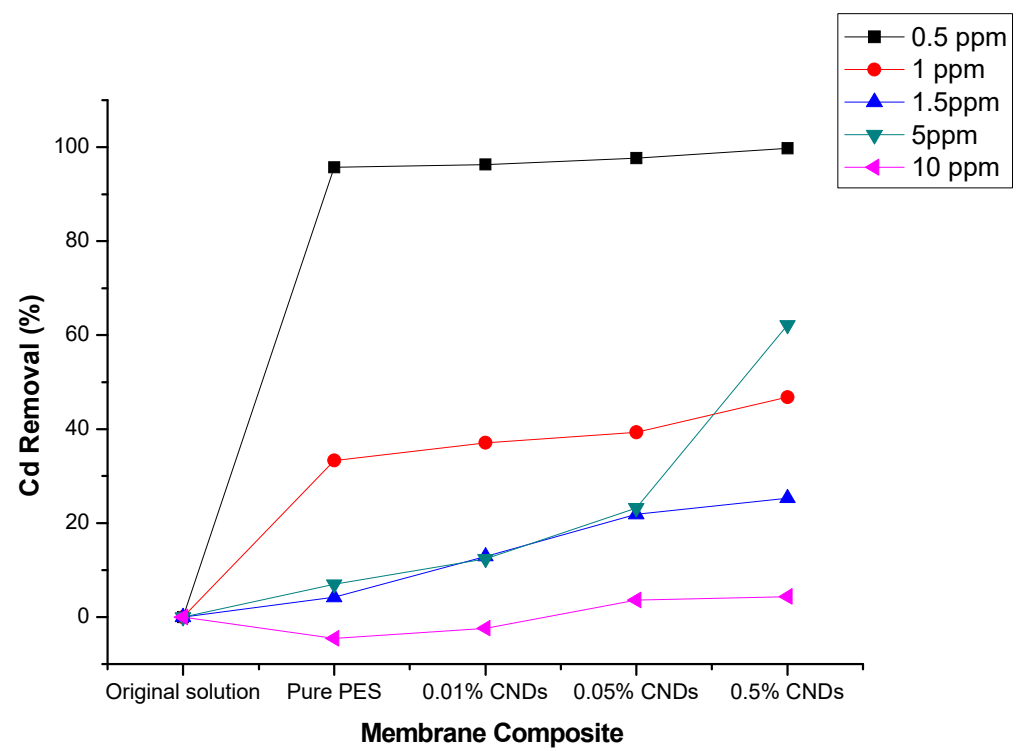

Figure 12. Effect of standard concentrations for the removal of cadmium(II) from standard solutions.

The concentration of $\mathrm{Cd}(\mathrm{II})$ decreased from 10 ppm-0.5 ppm caused a significant percentage of $\mathrm{Cd}^{2+}$ to be adsorbed by membranes. The $0.5 \mathrm{ppm}$ cadmium(II) was adsorbed most at pH 5 within $30 \mathrm{~min}$ by all the composite membranes. The percentage adsorbed increased with the increase in the percentage of the CNDs added onto the membranes. In Table 4 , the removal capacity of cadmium(II) by $0.5 \%$ CNDs/PES membranes was $0.70 \mathrm{mg} / \mathrm{cm}^{2}$ compared to other membranes and adsorbents.

Table 4. Comparison of differently modified PES membranes for $\mathrm{Cd}^{2+}$ removal from standard samples.

\begin{tabular}{|c|c|c|c|}
\hline Membrane & Detection Technique & $\% \mathrm{Cd}^{2+}$ Removal Capacity & Literature \\
\hline Cerium dioxide and composites & & $93.4 \mathrm{mg} / \mathrm{g}$ & [9] \\
\hline Carbon/zirconium oxide composite & AAS & $166.7 \mathrm{mg} / \mathrm{g}$ & [10] \\
\hline $\begin{array}{c}\text { Sulfonated } \\
\text { magnetic nano-particle adsorbents }\end{array}$ & AAS & $80.9 \mathrm{mg} / \mathrm{g}$ & [33] \\
\hline $\begin{array}{l}\text { Emulsion } \\
\text { liquid membrane }\end{array}$ & AAS & $0.44 \mathrm{mg} / \mathrm{mL}$ and $0.27 \mathrm{mg} / \mathrm{g}$ & [35] \\
\hline $\begin{array}{l}\text { A boehmite nanoparticle impregnated } \\
\text { electrospun fibre membrane }\end{array}$ & AAS & $0.20-0.21 \mathrm{mg} / \mathrm{g}$ & [36] \\
\hline $0.5 \%$ CNDs $/$ PES & GCESWASV & $0.70 \mathrm{mg} / \mathrm{cm}^{2}$ & Present work \\
\hline
\end{tabular}

\subsection{Interference Studies}

The detection of $\mathrm{Cd}^{2+}$ could be susceptible to interferences such as the presence of other divalent metal ions. According to the theory, the higher charge of the divalent ions tend to have stronger adsorption strengths compared to monovalent ions [37]. Hence interference studies were carried out at optimised conditions ( $0.5 \%$ CNDs / PES composite membrane, $\mathrm{pH} 5,30$ min contact time, and $0.5 \mathrm{ppm}$ concentration). The $0.5 \%$ CNDs $/ \mathrm{PES}$ membrane was used to adsorb cadmium(II) in the presence of lead(II), mercury(II) and copper(II) standard solutions. But after the addition of interfering ions, approximately $48 \%$ $\mathrm{Cd}^{2+}$ removal was achieved. 
The current signal of cadmium(II) was mostly suppressed in the presence of copper(II) and lead(II) before the adsorption of cadmium(II) as depicted in Figure 13. After the adsorption, copper(II) is also the most removed metal ion than cadmium(II) because $50 \%$ of copper(II) was removed instead of $\mathrm{Cd}^{2+}$. Therefore, $\mathrm{Cu}^{2+}$ and $\mathrm{Pb}^{2+}$ have significant interfering effect during the analysis of $\mathrm{Cd}^{2+}$ using GCE in ASV technique. For future work, this membrane can be further optimised to simultaneously remove the analyte and the interfering ions.

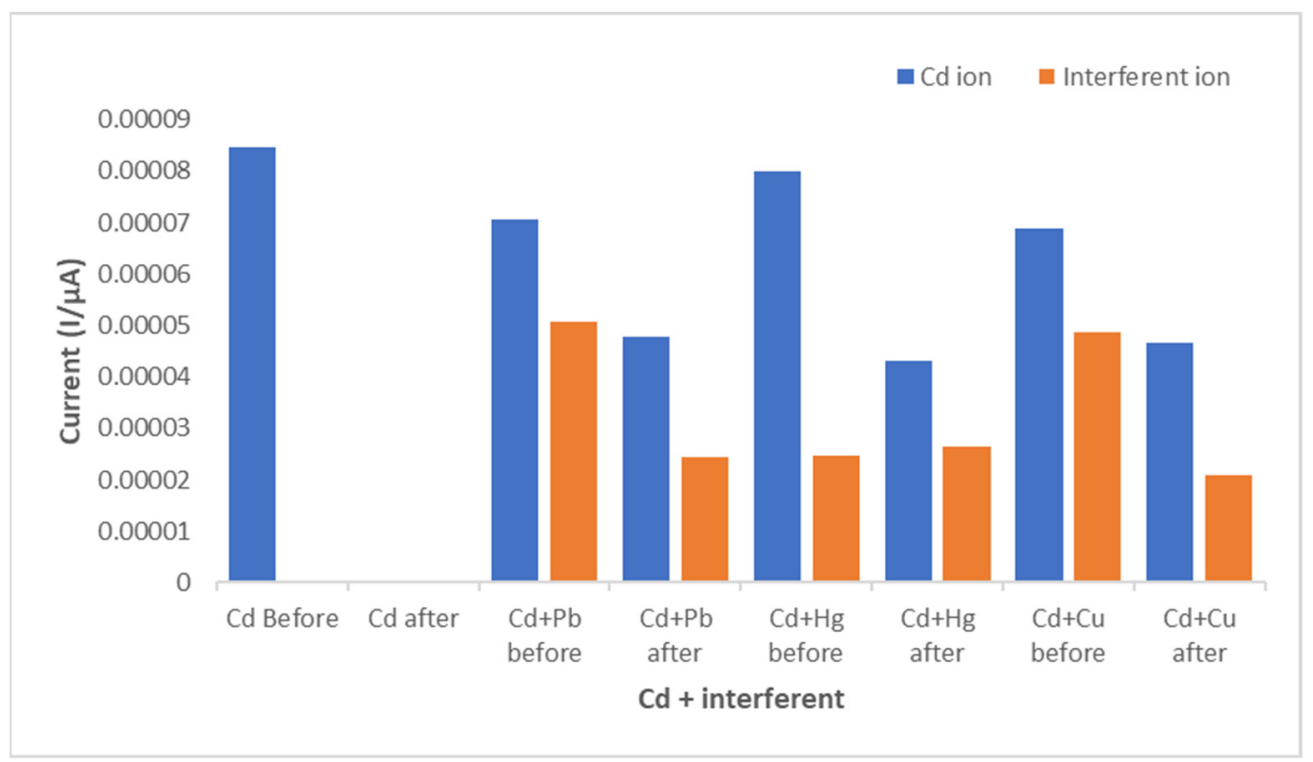

Figure 13. Interference studies during $\mathrm{Cd}^{2+}$ detection under optimized conditions.

\subsection{Reusability of $0.5 \%$ CNDs/PES for Cd(II) Removal}

The batch adsorption of cadmium(II) $0.5 \mathrm{ppm}$ standard solution was repeated by using the same membrane $(0.5 \% \mathrm{CNDs} / \mathrm{PES})$ at one-day intervals. After each analysis the membrane was stored in deionised water in the refrigerator and re-used after a day to examine its reusability. Figure 14 displayed that the membrane removed $99.78 \% \mathrm{Cd}^{2+}$ with relative standard deviation (RSD) of $\pm 3.4 \%$ after being analysed on each day. This confirmed that the membrane was consistent during the adsorption of $\mathrm{Cd}(\mathrm{II})$ for four days consecutively. After seven days, the membrane started to tear and the \% removal decreased from $99.78 \%$ to $95.56 \%$.

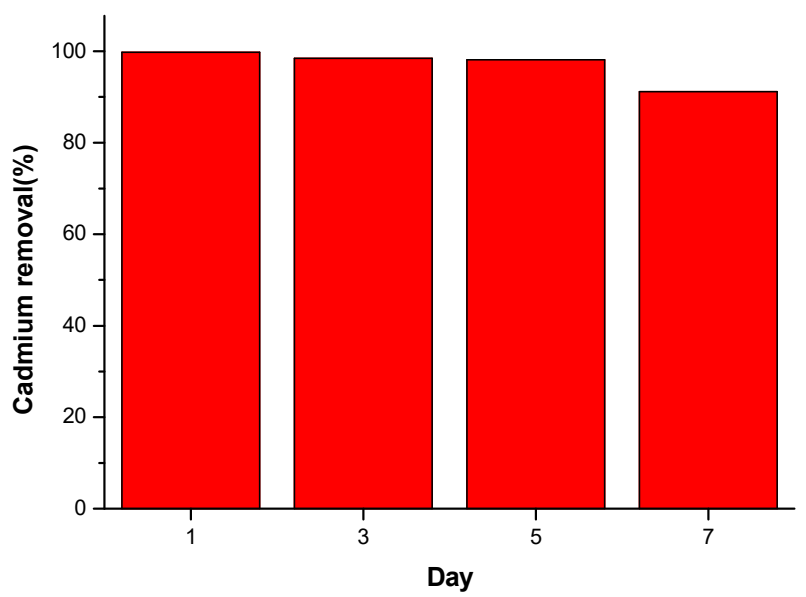

Figure 14. Membrane stability studies during the removal of $\mathrm{Cd}^{2+}$ and electrochemical sensing using GCE under optimized conditions. 


\subsection{The Removal of Cadmium(II) in Spiked Water Sample Using 0.5\% CNDs/PES}

The adsorption behaviour of $\mathrm{Cd}^{2+}$ was conducted on a tap water sample spiked with 3 ppm of $\mathrm{Cd}^{2+}$ as displayed in Figure 15. The concentration detected when using the ASV technique decreased from 3.02 to $1.11 \mathrm{ppm}$ for the spiked water sample, therefore $58.38 \%$ of $\mathrm{Cd}^{2+}$ was removed.

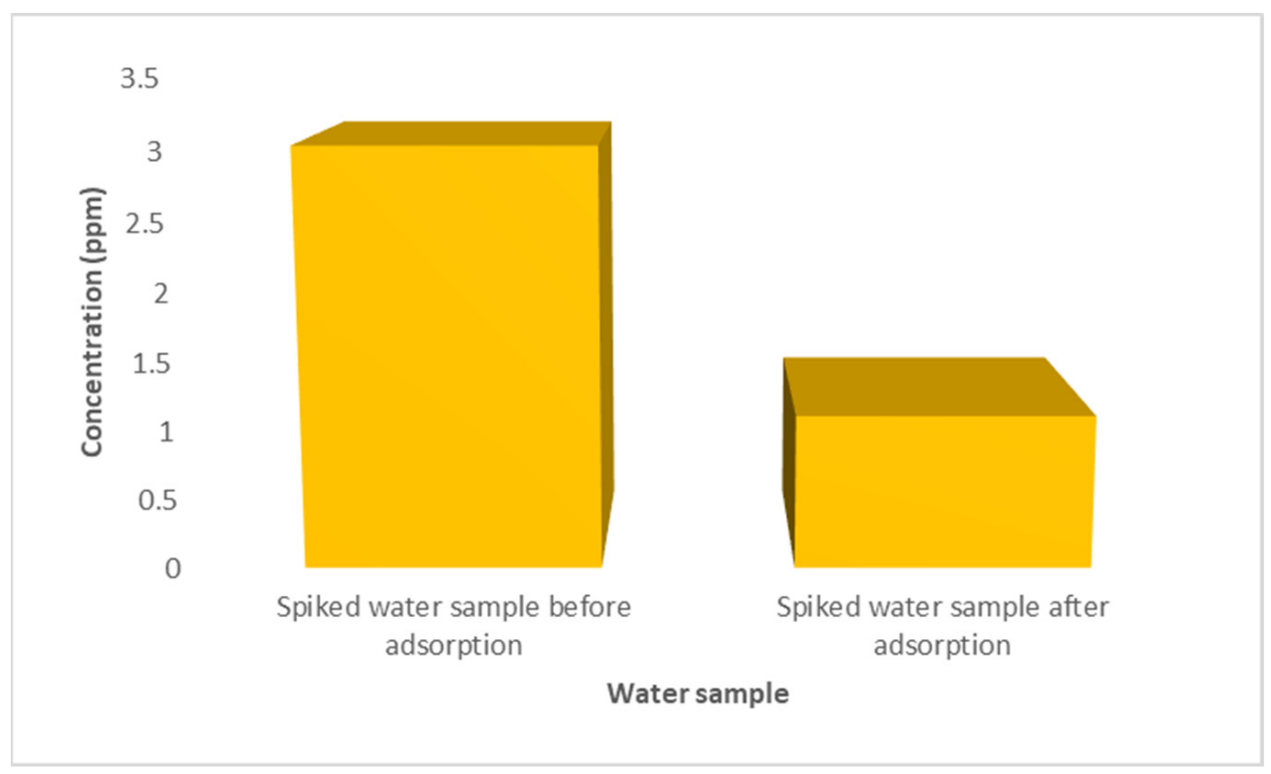

Figure 15. Tap water spiked with 3 ppm cadmium standard.

The comparison of ASV and ICP-OES methods was applied at $95 \%$ confidence level using $n=3$ of the spiked water sample. The value of $t_{\text {critical }}(6.452)$ was greater than $t_{\text {observed }}$ (4.303) for $\mathrm{Cd}^{2+}$. This result shows agreement with variation due to random error, and is thus a validation of the reported method.

\section{Conclusions}

The results confirmed that the CNDs were successfully embedded on the PES membrane via phase invasion. TEM displayed well-dispersed and spherical carbon nanodots with uniform shape and an average size of $6.7 \pm 2.8 \mathrm{~nm}$. The FTIR confirmed that the combination of PES with CNDs by an introduction of a new functionality at $3400 \mathrm{~cm}^{-1}$, which was attributed to -OH due to the presence of CNDs. Raman spectra established that blending the PES with CNDs increased the ID/IG ratio to $0.74,0.79,0.83$ and 0.82 for Pure CNDs, $0.01 \%$ CNDs/PES, $0.05 \%$ CNDs/PES and 0.5\% CNDs/PES respectively which means that the membrane maintained good structural integrity. SEM demonstrated a relatively spongy and porous surface as the amount of the CNDs was increased from $0.01 \%$ to $0.5 \%$ in CNDs/PES membranes. AFM results indicated that the surface roughness increased gradually with an increase in the amount of CNDs embedded onto the membranes $(0.01 \%$ CNDs/PES, $0.05 \%$ CNDs/PES and $0.5 \%$ CNDs/PES). The higher amount of CNDs coated on the PES reduced the contact angle and improved the hydrophilicity of the membranes. This enhancement in hydrophilicity was attributed to the presence of hydrophilic functional groups such as $-\mathrm{OH}$ and $\mathrm{COO}^{-}$found in the $\mathrm{CNDs}$ as reported in the FTIR analysis. The membrane performance tested by water flux showed that at a constant pressure of $300 \mathrm{kPa}$, the flux of pristine PES, $0.01 \%$ CNDs/PES, $0.05 \%$ CNDs/PES and $0.5 \% \mathrm{CNDs} / \mathrm{PES}\left(60.00,96.93,142.16\right.$ and $196.62 \mathrm{~L} \mathrm{~m}^{-2} \mathrm{~h}^{-1}$, respectively) increased proportionally with CNDs concentration in the membranes.

For the detection of cadmium(II) in water, the GCE was electrochemically characterised using CV at a potential range of -0.200 to $0.600 \mathrm{~V}$ and a scan rate of $50 \mathrm{mV} \mathrm{s}^{-1}$ in $\left[\mathrm{Fe}(\mathrm{CN})_{6}\right]^{-3 /-4}$ redox probe. The $\mathrm{Cd}^{2+}$ was detected by GCE in ASV under optimised 
parameters such as $0.1 \mathrm{M} \mathrm{HCl}$ (electrolyte), $200 \mathrm{~s}$ deposition time and $-900 \mathrm{mV}$ electrodeposition potential. The batch adsorption experiments displayed that the $0.5 \% \mathrm{CNDs} / \mathrm{PES}$ removed $99.78 \%$ of cadmium(II) from synthetic solutions when $\mathrm{pH}$, time and concentration of $\mathrm{Cd}^{2+}$ solution were optimised to 5,30 min and 0.5 ppm. The interference study showed that $\mathrm{Pb}^{2+}$ and $\mathrm{Cu}^{2+}$ competed with $\mathrm{Cd}^{2+}$ for adsorption on the active sites of the membrane surface, hence lower analyte percentage was detected in their presence. This scenario was also experienced in determination of $-\mathrm{Cd}^{2+}$ in spiked water sample, where $58.38 \% \mathrm{Cd}^{2+}$ was detected due to the sample matrix.

It established that the $0.5 \%$ CNDs/PES membrane is reusable because the same membrane was applied for four cycles to remove above $95 \%$ of cadmium(II) in water.

Author Contributions: N.M. was responsible for conceptualization, methodology, supervision, funding, resources, and manuscript review and editing. S.P.M. is a co-supervisor of the project, reviewed the manuscript and provided some of the resources. S.S. is responsible for formal analysis; investigation; writing - original draft preparation; writing-review and editing. All authors have read and agreed to the published version of the manuscript.

Funding: The research described in this paper was financially supported by the National Research Foundation of South Africa (Thuthuka Grant No. 107066 and TTK180427324698), the Centre for Nanomaterials Science Research, University of Johannesburg (UJ) South Africa and the Faculty of Science, (UJ) South Africa.

Institutional Review Board Statement: Not applicable in this study.

Informed Consent Statement: Not applicable in this study.

Data Availability Statement: The data supporting the study is saved in the Department of Chemical Sciences archives and Simanye Sam google drive. It is available upon request.

Acknowledgments: We would like to acknowledge the Electrochemistry Research Group, Nanomembrane Research Group, Luthando Tshwenya, Colani Fakude, Yolisa Bhembe, Nokalika Zwane, Khona Maziya and Koketso Shaku at the University of Johannesburg. We highly acknowledge E Mmutlane for editing the English in the manuscript.

Conflicts of Interest: The authors declare no conflict of interest.

\section{References}

1. Kang, A.J.; Baghdadi, M.; Pardakhti, A. Removal of cadmium and lead from aqueous solutions by magnetic acid-treated activated carbon nanocomposite. Desalination Water Treat. 2016, 57, 18782-18798. [CrossRef]

2. Bhuyan, M.S.; Bakar, M.A.; Akhtar, A.; Hossain, M.B. Heavy Metal Contamination in Surface Water and Sediment of the Meghna River, Bangladesh; Elsevier: Amsterdam, The Netherlands, 2017; pp. 273-279.

3. Olivera, S.; Chaitra, K.; Venkatesh, K.; Muralidhara, H.; Asiri, A.M.; Ahamed, M.I. Cerium dioxide and composites for the removal of toxic metal ions. Environ. Chem. Lett. 2018, 16, 1233-1246. [CrossRef]

4. Sharma, G.; Naushad, M. Adsorptive removal of noxious cadmium ions from aqueous medium using activated carbon/zirconium oxide composite: Isotherm and kinetic modelling. J. Mol. Liq. 2020, 310, 113025. [CrossRef]

5. Sivarajasekar, S.M.N.; Paramasivan, J.S.V.T.; Naushad, M. Phytoremediation of heavy metals: Mechanisms, methods and enhancements. Environ. Chem. Lett. 2018, 16, 1339-1359.

6. Sivarajasekar, N. Hevea brasiliensis-A Biosorbent for the Adsorption of $\mathrm{Cu}(\mathrm{II})$ from Aqueous Solutions. Carbon Lett. 2007, 8 , 199-206. [CrossRef]

7. Faisal, A.A.H.; Al-wakel, S.F.A.; Assi, H.A.; Naji, L.A.; Naushad, M.J. Waterworks sludge-filter sand permeable reactive barrier for removal of toxic lead ions from contaminated groundwater. J. Water Process Eng. 2020, 33, 101112. [CrossRef]

8. Ravindranath, N.A.; Jayaraman, V.; Gnanasekaran, T. Evaluation of cadmium concentration in vapour phase by a novel approach Sens. Actuators B Chem. 2018, 254, 59-63. [CrossRef]

9. Małecki, J.; Maron, A.M. Luminescence properties of copper(I), zinc(II) and cadmium(II) coordination compounds with picoline ligands. J. Lumin. 2017, 186, 127-134. [CrossRef]

10. Fatoki, O.S.; Awofolu, O.R. Levels of $\mathrm{Cd}, \mathrm{Hg}$ and $\mathrm{Zn}$ in some Surface Waters from the Eastern Cape Province, South Africa. Water $S A$ 2004, 29, 375-380. [CrossRef]

11. Street, R.A.; Kulkarni, M.G.; Stirk, W.A.; Southway, C.; Abdillahi, H.S.; Chinsamy, M.; Van Staden, J. Effect of cadmium uptake and accumulation on growth and antibacterial activity of Merwilla plumbea-An extensively used medicinal plant in South Africa. S. Afr. J. Bot. 2009, 75, 611-616. [CrossRef] 
12. Maleki, A.; Mahvi, A.H.; Zazouli, M.A.; Izanloo, H.; Barati, A.H. Aqueous cadmium removal by adsorption on barley hull and barley hull ash. Asian J. Chem. 2011, 23, 1373-1376.

13. Shi, L.; Li, X.; Li, Y.; Wen, X.; Li, J.; Choi, M.M.F.; Dong, C.; Shuang, S. Naked oats-derived dual-emission carbon nanodots for ratiometric sensing and cellular imaging. Sens. Actuators B Chem. 2015, 210, 533-541. [CrossRef]

14. Mathumba, P.; Kuvarega, A.T.; Dlamini, L.N.; Malinga, S.P. Synthesis and characterisation of titanium dioxide nanoparicles prepared within hyperbranched polyethylenimine polymer template using a modified sol-gel method. Mater. Lett. 2017, 195, 172-177. [CrossRef]

15. Cieśliński, J.T.; Krygier, K.A. Sessile droplet contact angle of water- $\mathrm{Al}_{2} \mathrm{O}_{3}$, water- $\mathrm{TiO}_{2}$ and water-Cu nanofluids. Exp. Therm. Fluid Sci. 2014, 59, 258-263. [CrossRef]

16. Kurniawan, T.A.; Chan, G.Y.; Lo, W.-H.; Babel, S. Physico-chemical treatment techniques for wastewater laden with heavy metals. Chem. Eng. J. 2006, 118, 83-98. [CrossRef]

17. Elektorowicz, M.; Muslat, Z. Removal of Heavy Metals from Oil Sludge Using Ion Exchange Textiles. Environ. Technol. 2008, 29, 393-399. [CrossRef]

18. Kasim, N.; Mohammad, A.W.; Abdullah, S.R.S. Performance of membrane filtration in the removal of iron and manganese from Malaysia's groundwater. Membr. Water Treat. 2016, 7, 277-296. [CrossRef]

19. Haan, T.Y.; Shah, M.; Chun, H.K.; Mohammad, A.W. A study on membrane technology for surface water treatment: Synthesis, characterization and performance test. Membr. Water Treat. 2018, 9, 69-77.

20. Zinadini, S. Preparation and characterization of high flux PES nanofiltration membrane using hydrophilic nanoparticles by phase inversion method for application in advanced wastewater treatment. JARWW 2016, 5, 232-235.

21. Ding, K.; Wang, P.; Zhao, J.; Li, Y.; Chen, Y.; Zhang, Y.; Wei, B.; Sun, Y. Carbon Nanodots Prepared from NaOH Boiled Graphene and Its Usage as a Support of PdO for Ethanol Oxidation Reaction; Elsevier: Amsterdam, The Netherlands, 2017; pp. 9766-9774.

22. Afkhami, A.; Saber-Tehrani, M.; Bagheri, H. Simultaneous removal of heavy-metal ions in wastewater samples using nanoalumina modified with 2,4-dinitrophenylhydrazine. J. Hazard. Mater. 2010, 181, 836-844. [CrossRef]

23. Zhu, W.; Gao, J.; Sun, S.; Zhang, S.; Chung, T.S. Poly (amidoamine) dendrimer (PAMAM) grafted on thin fi lm composite (TFC) nano fi ltration (NF) hollow fi ber membranes for heavy metal removal. J. Membr. Sci. 2015, 487, 117-126. [CrossRef]

24. Qu, P.; Tang, H.; Gao, Y.; Zhang, L.; Wang, S. Polyethersulfone Composite Membrane Blended. BioResources 2010, 5, $2323-2336$.

25. Cheng, Y.; Xu, C.; Kang, P.; Ping, S. Environmental effect of nitrogen-containing functionalization on the electrocatalytic activity of PtRu nanoparticles supported on carbon nanotubes for direct methanol fuel cells. Appl. Catal. B 2014, 158-159, 140-149. [CrossRef]

26. Sambaza, S.S.; Mhlanga, S.D.; Malinga, S.P.; Nxumalo, E.N. Fabrication of Novel PEI-Based Antimicrobial Metal-Organic Nanocomposites for the Treatment of Wastewater. Master's Thesis, University of Johannesburg, Johannesburg, South Africa, 2016.

27. Fahmi, M.Z.; Wathoniyyah, M.; Khasanah, M.; Rahardjo, Y.; Wafiroh, S.; Abdulloh, A. Incorporation of graphene oxide in polyethersulfone mixed matrix membranes to enhance hemodialysis membrane performance. RSC Adv. 2018, 8, 931-937. [CrossRef]

28. Orooji, Y.; Faghih, M.; Razmjou, A.; Hou, J.; Moazzam, P. Nanostructured mesoporous carbon polyethersulfone composite ultra fi ltration membrane with signi fi cantly low protein adsorption and bacterial adhesion. Carbon 2017, 111, 689-704. [CrossRef]

29. Yuan, Z.; Wu, X.; Jiang, X.Y.; Li, Y.; Huang, J.; Hao, L.; Zhang, J.; Wang, J. Carbon dots-incorporated composite membrane towards enhanced organic solvent nano filtration performance. J. Membr. Sci. 2018, 549, 1-11. [CrossRef]

30. Ahmad, A.; Abdulkarim, A.; Ooi, B.; Ismail, S. Recent development in additives modifications of polyethersulfone membrane for flux enhancement. Chem. Eng. J. 2013, 223, 246-267. [CrossRef]

31. Vatanpour, V.; Siavash, S.; Moradian, R.; Zinadini, S.; Astinchap, B. Fabrication and characterization of novel antifouling nanofiltration membrane prepared from oxidized multiwalled carbon nanotube/polyethersulfone nanocomposite. J. Membr. Sci. 2011, 375, 284-294. [CrossRef]

32. Koulivand, H.; Shahbazi, A.; Vatanpour, V.; Rahmandoust, M. Development of carbon dot-modified polyethersulfone membranes for enhancement of nanofiltration, permeation and antifouling performance. Sep. Purif. Technol. 2020, 230, 115895. [CrossRef]

33. Chen, K.J.; He, Y.; Li, X.; Cai, K.; Zhang, T.; Liu, Y.; Hu, D.; Lin, L.; Kong, J.; Liu, K.; et al. Removal of cadmium and lead ions from water by sulfonated magnetic nano-particle adsorbents. J. Colloid Interface Sci. 2017, 494, 307-316. [CrossRef] [PubMed]

34. Tshwenya, L.; Omotayo, A.A. Ethylenediamine functionilized carbon nanoparticles: Synthesis, characterization, and evaluation for cadmium removal in water. RCS 2017, 7, 34226-34235.

35. Mortaheb, H.; Kosuge, H.; Mokhtarani, B.; Amini, M.H.; Banihashemi, H.R. Study on removal of cadmium from wastewater by emulsion liquid membrane. J. Hazard. Mater. 2009, 165, 630-636. [CrossRef] [PubMed]

36. Hota, G.; Kumar, B.R.; Ng, W.J.; Ramakrishna, S. Fabrication and characterization of a boehmite nanoparticle impregnated electrospun fiber membrane for removal of metal ions. J. Mater. Sci. 2007, 43, 212-217. [CrossRef]

37. Adapa, S.; Malani, A. Role of hydration energy and co-ions association on monovalent and divalent cations adsorption at mica-aqueous interface. Sci. Rep. 2018, 8, 1-12. [CrossRef] [PubMed] 